\title{
A Unilateral Accident Model Under Ambiguity
}

Joshua C. Teitelbaum

Georgetown University Law Center, jct48@law.georgetown.edu

This paper can be downloaded free of charge from:

https://scholarship.law.georgetown.edu/facpub/608

http://ssrn.com/abstract=881849

36 J. Legal Stud. 431-477 (2007)

This open-access article is brought to you by the Georgetown Law Library. Posted with permission of the author. Follow this and additional works at: https://scholarship.law.georgetown.edu/facpub

Part of the Torts Commons 


\title{
A Unilateral Accident Model under Ambiguity
}

\author{
Joshua C. Teitelbaum
}

\begin{abstract}
Standard accident models are based on the expected utility framework and represent agents' beliefs about accident risk with a probability distribution. Consequently, they do not allow for Knightian uncertainty, or ambiguity, with respect to accident risk and cannot accommodate optimism (ambiguity loving) or pessimism (ambiguity aversion). This paper presents a unilateral accident model under ambiguity. To incorporate ambiguity, I adopt the Choquet expected utility framework and represent the injurer's beliefs with a neoadditive capacity. I show that neither strict liability nor negligence is generally efficient in the presence of ambiguity. In addition, I generally find that the injurer's level of care decreases (increases) with ambiguity if he is optimistic (pessimistic) and decreases (increases) with his degree of optimism (pessimism). The results suggest that negligence is more robust to ambiguity and, therefore, may be superior to strict liability in unilateral accident cases. Finally, I design an efficient ambiguity-adjusted liability rule.
\end{abstract}

\section{INTRODUCTION}

Fathered by Coase (1960), the economic analysis of tort law lies at the foundation of modern law and economics. The workhorse of tort law and economics is the basic accident model, which was first formalized in Brown (1973) and later expounded in Shavell (1987) and Landes and Posner (1987). ${ }^{1}$ The basic accident model provides a framework for

Joshua C. Teitelbaum is Visiting Assistant Professor at Cornell Law School and a doctoral candidate in the Department of Economics at Cornell University. This paper is based on a chapter of my dissertation. I wish to thank Larry Blume, Steve Coate, Rick Geddes, Ani Guerdjikova, Eric Posner, an anonymous referee, seminar participants at Cornell University, and conference participants at the sixteenth annual meeting of the American Law and Economics Association for their comments and feedback. Any errors are my own.

1. A more recent comprehensive treatment of the basic accident model is contained in Miceli (1997).

[Journal of Legal Studies, vol. 36 (June 2007)]

(C) 2007 by The University of Chicago. All rights reserved. 0047-2530/2007/3602-0016\$10.00 
analyzing the effects of liability rules on agents' incentives to take care against accidents and, therefore, on the social costs of accidents. Consequently, it has been widely used to examine positive and normative questions about the efficiency and suitability of alternative liability rules. $^{2}$

Standard formulations of the basic accident model assume that agents are expected utility maximizers in conformity with the decision theories of von Neumann and Morgenstern (1944), Savage (1954), or Anscombe and Aumann (1963). Under expected utility theory, ${ }^{3}$ agents are assumed to make decisions under uncertainty as if they assign a probability distribution over the set of possible events and choose an act from the set of available acts that maximizes the expected value of a utility function with respect to such probability distribution. Because of its mathematical simplicity and normative appeal, as well as the explanatory power of many of its predictions, expected utility theory is the dominant framework for the analysis of individual decision making under uncertainty in economics.

Notwithstanding its primacy, there have been many challenges to expected utility theory as a positive decision theory. One of the most famous is the paradox of Ellsberg (1961). One version of the Ellsberg paradox goes as follows. There are two urns. Urn 1 contains 50 red balls and 50 black balls. Urn 2 contains 100 red and black balls in an unknown proportion. Subjects engage in two gambles. In gamble A, subjects receive $\$ 100$ if they draw a red ball and nothing if they draw a black ball. In gamble B, subjects receive $\$ 100$ if they draw a black ball and nothing if they draw a red ball. Before each gamble, subjects choose the urn from which they prefer to draw the ball. Most subjects in this situation choose to draw from urn 1 in both gambles (see Becker and Brownson 1964). This result, however, is paradoxical to expected utility theory, for it would imply that the assigned probability of drawing a red ball from urn 2 is less than one-half in gamble $\mathrm{A}$ and greater than one-half in gamble B. In other words, these subjects are not acting as if they assigned probabilities to uncertain events, and therefore expected utility theory cannot explain their choices.

The Ellsberg paradox highlights the significance of ambiguity for

2. I adhere to the view that efficiency is the appropriate normative goal of the legal system. In defense of this view, see Kaplow and Shavell (2001, 2002b).

3. I use the term "expected utility theory" broadly to encompass objective expected utility theory as formulated by von Neumann and Morgenstern (1944) as well as subjective expected utility theory as formulated by Savage (1954) and Anscombe and Aumann (1963). 
individual decision making. Knight (1921) made a distinction between risk-uncertain events with specified probabilities-and uncertaintyuncertain events with unspecified or ambiguous probabilities. The approach of expected utility theory, however, obviates this distinction. As a result, models based on the expected utility framework, including the basic accident model, do not allow for Knightian uncertainty, which has come to be known in the literature as ambiguity, and therefore cannot capture different attitudes toward or reactions to ambiguity, including ambiguity loving, or optimism, and ambiguity aversion, or pessimism.

Psychology research suggests that people exhibit optimism and pessimism in the accident context. Optimism has been found to be robust with respect to a variety of accident risks (see, for example, Weinstein 1980, 1989, 1999; Sunstein 1997; Jolls 1998). In the case of traffic accidents, for example, studies have found that while people's beliefs about societal accident risks are fairly accurate (see, for example, Lichtenstein et al. 1978), people generally are optimistic with respect to the likelihood that they will cause or otherwise be involved in an accident (see Svenson 1981; Svenson, Frischhoff, and MacGregor 1985; Finn and Bragg 1986; Matthews and Moran 1986; DeJoy 1989; McKenna, Stanier, and Lewis 1991; Guppy 1992). Pessimism tends to be displayed with respect to the risk of accidents that are "available"-for example, highly salient, perhaps owing to media attention; dramatic or catastrophic in nature; intrinsically vivid, imaginable, or memorable; or technological in nature (see Sunstein 1997; Jolls 1998; Jolls, Sunstein, and Thaler 1998; Gigerenzer 2005; see also Slovic, Frischhoff, and Lichtenstein 1982; Covello and Johnson 1987; Viscusi and Magat 1987; Viscusi 1992). This research calls for the modification of the basic accident model to allow for ambiguity.

The Ellsberg paradox and subsequent experimental evidence of the importance of attitudes toward ambiguity for decisions ${ }^{4}$ have inspired various alternatives to and generalizations of expected utility theory to accommodate ambiguity. ${ }^{5}$ One of the most influential axiomatic generalizations of expected utility theory that accommodates ambiguity is Choquet expected utility theory, which was pioneered by Schmeidler

4. For a more detailed discussion of the Ellsberg paradox and a survey of the related experimental evidence, see Camerer (1995).

5. For a survey of alternatives to and generalizations of expected utility theory, including those that accomodate ambiguity, see Camerer and Weber (1992). 
(1989). ${ }^{6}$ Under Choquet expected utility theory, agents' beliefs about the likelihood of uncertain events are represented with a nonadditive probability called a capacity. ${ }^{7}$ Agents are assumed to act so as to maximize the expected value of a utility function with respect to such capacity, which is calculated using the Choquet (1954) integral. The nonadditivity of the capacity allows for different attitudes toward ambiguity. In particular, a concave (superadditive) capacity reflects optimism, while a convex (subadditive) capacity reflects pessimism (see Schmeidler 1989; Wakker 2001). ${ }^{8}$ Choquet expected utility with a convex capacity, for instance, can capture pessimism as exemplified by the Ellsberg paradox. ${ }^{9}$

This paper presents a unilateral accident model under ambiguity. ${ }^{10}$ Specifically, it generalizes the basic unilateral accident model to allow for ambiguity by assuming the injurer is a Choquet expected utility maximizer and representing the injurer's beliefs about accident risk with a special type of capacity called a neoadditive capacity, which was introduced by Chateauneuf, Eichberger, and Grant (forthcoming). Choquet expected utility with a neoadditive capacity is the simplest generalization of expected utility that can accommodate optimistic and pessimistic reactions to ambiguity. It assumes that an agent makes decisions under uncertainty as if he ${ }^{11}$ believes, with incomplete confidence, that a specified probability distribution describes the likelihood of uncertain events and chooses an act from the set of available acts that maximizes a weighted sum of the minimum utility, the maximum utility,

6. Schmeidler (1989) and Gilboa (1987) axiomatize Choquet expected utility in the Anscombe and Aumann (1963) and Savage (1954) frameworks, respectively. An additional axiomatization of Choquet expected utility is provided by Sarin and Wakker (1992).

7. Expected utility is a special case of Choquet expected utility in which the capacity is additive (that is, a probability). A capacity $\mu$ is additive if $\mu(E)+\mu(F)=\mu(E \cup F)$ for all mutually exclusive events $E$ and $F$.

8. A capacity $\mu$ is convex if $\mu(E)+\mu(F) \leq \mu(E \cup F)$ for all mutually exclusive events $E$ and $F$. It is concave if the reverse inequality holds.

9. A predecessor to Choquet expected utility theory is Shackle's $(1949,1955,1961)$ nonprobabilistic theory of individual decision making under uncertainty. Although Shackle's theory was widely discussed in the 1950s and still constitutes a main reference point for economists working in the Keynesian and Austrian traditions, it largely has been disregarded by neoclassical economists and modern decision theorists (Basili and Zappia 2003a, 2003b). For a thorough discussion of Schakle's theory, including its critics in the 1950s, its relation to Choquet expected utility theory, and its place in the Keynesian and Austrian traditions, see Basili and Zappia (2000, 2003a, 2003b, 2006) and Zappia and Basili (2005).

10. In unilateral accidents, the injurer, but not the victim, can take care to reduce expected accident losses.

11. For simplicity, this paper uses masculine pronouns throughout. 
and the expected utility with respect to such probability distribution. The parameters of the model allow me to measure the injurer's degree of ambiguity, which is the complement of his degree of confidence, and his degrees of optimism and pessimism, which determine the weights assigned to the maximum utility and the minimum utility. As a result, I can perform comparative statics on changes in optimism, pessimism, and ambiguity. ${ }^{12}$

I show that in the basic unilateral accident setting neither strict liability nor negligence is generally efficient in the presence of ambiguity. In particular, I show that (1) in the case of fixed accident losses (when the injurer's level of care does not affect the magnitude of accident losses), the injurer will exercise too little care under strict liability and may exercise too little care under negligence, and (2) in the case of variable accident losses (when the injurer's level of care does affect the magnitude of accident losses), the injurer may exercise too little or too much care under strict liability and may exercise too little care under negligence. In addition, I find that, in general, the injurer's level of care (1) decreases with his degree of optimism and increases with his degree of pessimism and (2) decreases with ambiguity if he is optimistic and increases with ambiguity if he is pessimistic. The results are in contrast to the standard results of the basic unilateral accident model: namely, in both cases on accident losses, the injurer will take optimal care under strict liability and negligence. The results suggest that negligence is more robust to ambiguity and, therefore, may be superior to strict liability in unilateral accident cases. Finally, I design and demonstrate the efficiency of an ambiguity-adjusted liability rule.

This paper contributes to strands of the law and economics and the applied decision theory literatures. Within the law and economics literature, this paper is the first to adopt the Choquet expected utility framework to incorporate ambiguity with respect to accident risk into the basic accident model. ${ }^{13}$ As such, it contributes to the well-established

12. Closely related to Choquet expected utility with a neoadditive capacity is $\alpha$-maxmin expected utility with multiple priors (Ghirardato, Maccheroni, and Marinacci 2004). Under this approach, ambiguity is represented by a set of probability distributions, and optimism and pessimism correspond to the weights applied to the maximum and minimum expected utility over the set of probability distributions.

13. There are many papers that study the effects of uncertainty with respect to other aspects of the basic accident model (see footnotes 22-23). Shavell (1992) considers a situation in which agents face uncertainty about accident risk, but he examines the incentives that alternative liability rules create for injurers to obtain information about accident risk and whether these incentives are socially optimal. There are a limited number of papers 
literature on the economics of tort law (for surveys, see Bouckaert and De Geest 2000, pt. 3; Kaplow and Shavell 2002a, pp. 1667-82; Mattiacci and Parisi 2005) and to the burgeoning behavioral law and economics literature. ${ }^{14}$ Within the applied decision theory literature, this paper adds to the growing number of applications of Choquet expected utility theory to accommodate ambiguity (for a survey, see Mukerji and Tallon 2004), including applications that use neoadditive capacities to represent beliefs (see, for example, Schipper 2005; Eichberger and Kelsey 2006; Ford, Kelsey, and Pang 2006; Eichberger, Kelsey, and Schipper 2007; Chateauneuf, Eichberger, and Grant, forthcoming).

Most closely related to this paper are Posner (2003), Eide (2005, 2007), and Bigus (2006). Posner (2003) introduces optimism about lowprobability accidents into the basic unilateral accident model by assuming agents know the probability of an accident when it is above some threshold but treat accident probabilities below the threshold as though they were zero. For the case of fixed accident losses, he finds that, under both strict liability and negligence, agents might take too much or too little care for sufficiently high levels of optimism and will take optimal care for sufficiently low levels of optimism. Posner also analyzes the case of variable activity levels and briefly discusses bilateral accidents, neither of which I address in this paper. However, he does not consider the case of unilateral accidents with variable accident losses, which I do. Eide $(2005,2007)$ and Bigus (2006) analyze the basic accident model under rank-dependent expected utility theory (Quiggin 1982, 1993) and prospect theory (Kahneman and Tversky 1979), respectively. ${ }^{15}$ For the case of unilateral accidents, Eide finds that under strict liability the injurer may take too much or too little care depending on the slope of the probability weighting function and that under negligence the injurer may take too little care if he substantially underweights the probability of an

that consider the effects of ambiguity on the economic analysis of other areas of law, for example, taxation (Jolls 1998; Chorvat 2002) and the criminal process (Segal and Stein 2006).

14. Sunstein (1997) and Jolls, Sunstein, and Thaler (1998) were early calls for the modification of standard law and economics models to reflect advances in behavioral economics and decision theory. Sunstein (2000) and Parisi and Smith (2005) are recent collections of behavioral law and economics papers.

15. Rank-dependent expected utility theory is a special case of Choquet expected utility theory in which the agent's capacity is an increasing probability weighting function (see Wakker 1990; Hong and Wakker 1996). Prospect theory is an alternative decision theory that is not directly related to Choquet expected utility theory. However, cumulative prospect theory (Tversky and Kahneman 1992) is a generalization of Choquet expected utility theory that permits different treatment of gains and losses (see Tversky and Wakker 1995). 
accident. Bigus finds that the injurer will take too little care under strict liability and may take too little care under negligence depending on the slope of the probability weighting function. These findings are consistent with the results of this paper. Eide and Bigus also study bilateral accidents and vague standards of due care, respectively. Neither paper, however, distinguishes the cases of fixed and variable accident losses or performs comparative statics.

The remainder of the paper is organized as follows. Section 2 presents the model. It describes the basic setup and explains how ambiguity about accident risk is modeled by Choquet expected utility with a neoadditive capacity. Section 3 states the results of the model in the absence of ambiguity, which correspond to the standard results of the basic unilateral accident model, and derives the results of the model in the presence of ambiguity. Section 4 develops a simple numerical example to illustrate the model's results. Section 5 discusses certain implications of the model and designs an ambiguity-adjusted liability rule that is efficient in the presence of ambiguity. Section 6 concludes the paper and suggests directions for future research. Appendix A contains a formal description of the Choquet expected utility framework for the paper. Appendix B presents the proofs of an assertion and several propositions stated but not proved in the body of the paper.

\section{THE MODEL}

\subsection{Basic Setup}

The model is based on the basic unilateral accident model of Shavell (1987). There are two agents—an injurer and a victim—and a numeraire good-income-in terms of which all payoffs and costs are defined. Both agents are risk neutral, and their Bernoulli utility of income is equal to income. The agents are strangers and not parties to any contract or market transaction, and transaction costs are sufficiently high to preclude Coasean bargaining.

Each agent engages in a risky activity from which he receives a payoff. For example, the injurer could be driving a car, and the victim could be a pedestrian. Let $k>0$ denote the payoff to the injurer from engaging in his activity, and normalize the victim's payoff to be zero. The injurer, but not the victim, has the ability to choose a level of care, expressed in terms of its cost, to exercise when engaging in his activity. Let $c \geq 0$ denote the level of care exercised by the injurer. An accident involving 
the injurer and the victim occurs with probability $\pi \in(0,1]$. In the event of an accident, the victim incurs accident losses $l>0$. Hence, expected accident losses are $L=\pi l$.

I consider two cases of accident losses: fixed accident losses and variable accident losses. In the case of fixed accident losses, the injurer can take care to reduce the probability of an accident, but the magnitude of accident losses is fixed. Thus, expected accident losses are $L(c)=\pi(c) l$. In the case of variable accident losses, the injurer can take care to reduce the probability of an accident and the magnitude of accident losses, and therefore expected accident losses are $L(c)=\pi(c) l(c)$. In both cases, I assume that $\pi(c)$ is twice continuously differentiable, strictly decreasing, and strictly convex- $\pi^{\prime}(c)<0$ and $\pi^{\prime \prime}(c)>0$. In the case of variable accident losses, I further assume that $l(c)$ is twice continuously differentiable, strictly decreasing, and strictly convex- $l^{\prime}(c)<0$ and $l^{\prime \prime}(c)>0$.

Whether the victim receives compensation from the injurer for accident losses depends on the applicable liability rule. I consider three liabilities rules: (1) no liability, under which the victim receives no compensation from the injurer, regardless of the level of care exercised by the injurer, (2) strict liability, under which the victim receives full compensation for his accident losses from the injurer, regardless of the injurer's level of care, and (3) negligence, under which the victim receives full compensation for his accident losses if the injurer fails to meet the applicable standard of due care, denoted $\bar{c}$. In modern Anglo-American law, negligence is the general basis for liability in cases of accidents among noncontracting parties or strangers. Strict liability applies only in certain accident cases, including cases in which the injurer engages in an abnormally dangerous activity or manufactures a defective product, certain nuisance and trespass cases, and cases involving certain environmental harms (see Dobbs 2001).

\subsection{Modeling Ambiguity}

In a departure from the basic unilateral accident model, I assume the injurer faces ambiguity with respect to accident risk. To incorporate ambiguity into the model, I assume the injurer is a Choquet expected utility maximizer whose beliefs about accident risk may be represented

with a neoadditive capacity $\nu$ based on $\pi \cdot{ }^{16}$ For simplicity, I assume the victim is an expected utility maximizer.

16. More precisely, $\nu$ is based on the probability distribution $\{\pi, 1-\pi\}$. To simplify the notation, however, I occassionally let $\pi$ stand for the probability distribution $\{\pi, 1-\pi\}$. 
Formally, I assume the injurer's belief about the likelihood of an accident is given by $\nu(\pi)=\delta(1-\alpha)+(1-\delta) \pi(c)$, where $\delta, \alpha \in[0,1]$, and I normalize $\nu(0)=0$ and $\nu(1)=1$. Similarly, the injurer's belief about the likelihood of no accident is given by $\nu(1-\pi)=\delta(1-\alpha)+$ $(1-\delta)[1-\pi(c)]$. Note that, in general, the injurer's beliefs are nonadditive: $\nu(\pi)+\nu(1-\pi) \neq 1$ unless $\delta=0$ or $\alpha=\frac{1}{2}$. Given his beliefs, the injurer's Choquet expected utility of exercising level of care $c$ under a rule of no liability or strict liability is

$$
V_{\pi}(c)=\delta \alpha m(c)+\delta(1-\alpha) M(c)+(1-\delta) E_{\pi}(c),
$$

where $m(c), M(c)$, and $E_{\pi}(c)$ denote the minimum utility, the maximum utility, and the expected utility with respect to $\pi$, respectively, of exercising level of care $c$ given the applicable liability rule. Under a negligence rule, the injurer effectively faces no liability if he satisfies the standard of due care $(c \geq \bar{c})$ and faces strict liability otherwise $(c<\bar{c})$. Thus, the injurer's Choquet expected utility of exercising level of care $c$ under a negligence rule is ${ }^{17}$

$$
\begin{cases}V_{\pi}(c) \text { under no liability } & \text { if } c \geq \bar{c} \\ V_{\pi}(c) \text { under strict liability } & \text { if } c<\bar{c} .\end{cases}
$$

Note that because there are only two possible events-accident or no accident-and given the basic setup of the model, under each liability rule the minimum utility $m(c)$ is the outcome in the event of an accident, the maximum utility $M(c)$ is the outcome in the event of no accident, and the expected utility $E_{\pi}(c)$ is the expected outcome $\pi(c) m(c)+[1-$ $\pi(c)] M(c)$. Accordingly, equation (1) can be rewritten as

$$
V_{\pi}(c)=[\delta \alpha+(1-\delta) \pi(c)] m(c)+\{\delta(1-\alpha)+(1-\delta)[1-\pi(c)]\} M(c) .
$$

From equation (2) we can see that in evaluating the Choquet expected utility of exercising level of care $c$, the injurer assigns weight $\delta \alpha+$ $(1-\delta) \pi(c)$ to the accident outcome, $m(c)$, and weight $\delta(1-\alpha)+(1-$ $\delta)[1-\pi(c)]$ to the no-accident outcome, $M(c)$. It is important to note that these weights are not subjective probabilities corresponding to the injurer's beliefs about accident risk but rather are decision weights generated by a neoadditive capacity based on $\pi$ that represents his nonadditive beliefs. ${ }^{18}$ In particular, the weight assigned to the accident out-

17. Technical details underlying $\nu$ and $V_{\pi}$ are supplied in Appendix A.

18. For a detailed discussion of capacities and decision weights, see Sarin and Wakker (1998). 
come, $\delta \alpha+(1-\delta) \pi(c)$, does not correspond to the injurer's belief about the likelihood of an accident, $\nu(\pi) .{ }^{19}$

Intuitively, representing the injurer's beliefs about accident risk with a neoadditive capacity based on $\pi$ assumes the injurer believes the probability of an accident is $\pi$ but lacks confidence in this belief. The injurer's degree of confidence is measured by $(1-\delta)$. It is the weight the injurer puts on $\pi$ in his capacity and on $E_{\pi}$ in his utility function. The degree of ambiguity is measured by $\delta$. It represents the degree to which the injurer lacks confidence in $\pi$. The injurer reacts to ambiguity by overweighting either the outcome in the event of an accident, $m$, or the outcome in the event of no accident, $M$. If the injurer overweights the accident outcome, he is pessimistic. If he overweights the no-accident outcome, he is optimistic. Which outcome the injurer overweights depends on the parameter $\alpha$. If $\alpha>\pi$, the injurer overweights the accident outcome; if $\alpha<\pi$, the injurer overweights the no-accident outcome. ${ }^{20}$ Accordingly, I interpret $\alpha$ as the injurer's degree of pessimism and $1-$ $\alpha$ as his degree of optimism. Note that if there is no ambiguity $(\delta=0)$ or if the injurer is neither optimistic nor pessimistic $(\alpha=\pi)$, then Choquet expected utility with respect to $\nu$ based on $\pi$ reduces to expected utility with respect to $\pi$ (that is, $V_{\pi}=E_{\pi}$ ), and the model reduces to the standard unilateral accident model. ${ }^{21}$

In order to focus on the effects of ambiguity on the standard results of the basic unilateral accident model, I assume there is no uncertainty with respect to any other aspect of the model. ${ }^{22}$ For example, I assume that the agents know the applicable legal standards and that the court accurately determines all relevant facts, including the probability of an

19. In fact, they coincide only if there is no ambiguity $(\delta=0)$, the injurer is neither optimistic nor pessimistic $(\alpha=\pi)$, or the injurer reacts to ambiguity with equal degrees of optimism and pessimism $\left(\alpha=\frac{1}{2}\right)$. Note, however, that the weight assigned to the noaccident outcome, $\delta(1-\alpha)+(1-\delta)[1-\pi(c)]$, does correspond to the injurer's belief about the likelihood of no accident, $\nu(1-\pi)$, and that $\delta \alpha+(1-\delta) \pi(c)=1-\nu(1-\pi)$. The former reflects a general property of Choquet expected utility with a neoadditive capacity, namely, that the weight assigned to the best outcome corresponds to the agent's capacity of the best outcome (see Eichberger and Kelsey 2006). The latter reflects the peculiar fact of the model that there are only two outcomes. It does not hold in the general case in which there are more than two outcomes (see Eichberger and Kelsey 2006).

20. To see this, note that $\delta \alpha+(1-\delta) \pi>\pi$ if and only if $\alpha>\pi$ and that $\delta(1-\alpha)+$ $(1-\delta)(1-\pi)>1-\pi$ if and only if $\alpha<\pi$.

21. To see that $V_{\pi}(c)=E_{\pi}(c)$ if there is no ambiguity, simply substitute $\delta=0$ into equation (1). To see that $V_{\pi}(c)=E_{\pi}(c)$ if the injurer is neither optimistic nor pessimistic, substitute $\alpha=\pi$ into equation (2) and recall that $E_{\pi}(c)=\pi(c) m(c)+[1-\pi(c)] M(c)$.

22. Shavell (1987) and Miceli (1997) provide textbook coverage of various models that introduce uncertainty with respect to other aspects of the basic accident model. 
accident, the magnitude and incidence of accident losses, and the agents' preferences and acts. ${ }^{23}$ In addition, I abstract from other complexities that have been introduced in the literature, such as bilateral care, variable activity levels, bilateral harm, risk aversion, and the judgment-proof problem. ${ }^{24}$

\subsection{Remarks}

Before turning to the results of the model, I conclude this section with a few general remarks regarding Choquet expected utility with a neoadditive capacity.

2.3.1. Capacities and Ambiguity. A capacity can capture different ambiguity attitudes because it is nonadditive. To illustrate, I will show how a convex neoadditive capacity can capture ambiguity aversion, or pessimism, as exemplified by a preference for urn 1 (the unambiguous urn) in both gambles in the Ellsberg paradox. Let $u(x)$ denote the utility of prize $x$ and normalize $u(0)=0$. Consider an agent who evaluates gambles according to expected utility and whose belief about the likelihood of drawing a red ball from urn 2 (the ambiguous urn) is given by a probability $p$. A preference for urn 1 in gamble A implies $\frac{1}{2} u(100)+$ $\frac{1}{2} u(0)>p u(100)+(1-p) u(0)$, or $\frac{1}{2}>p$, and a preference for urn 1 in gamble B implies $\frac{1}{2} u(0)+\frac{1}{2} u(100)>p u(0)+(1-p) u(100)$, or $\frac{1}{2}>1-p$. Combining these conditions gives $p+(1-p)<1$, which contradicts the additivity of $p$. This illustrates the paradox. It also illustrates that ambiguity aversion is akin to subadditivity. Next consider an agent who evaluates gambles according to Choquet expected utility and whose belief about the likelihood of a drawing a red ball from urn 2 is given by a convex neoadditive capacity $\mu$ based on $p$. In addition, assume the

23. Craswell and Calfee (1986) present an accident model in which defendants face uncertainty about the applicable legal standards. Shavell (1985) presents an accident model in which courts face uncertainty about causation. Hylton (1990) presents an accident model in which courts are unable to determine accurately in every case whether the defendant acted negligently.

24. I restrict attention to unilateral care because it is the primitive form of the basic accident model. In conformity with the basic accident model, I assume that the agents' activity levels are fixed and do not affect expected accident losses, that only the victim incurs accident losses, and that the agents are risk neutral. Shavell (1980) introduces the issue of the choice of activity level to the basic accident model. Leong (1989) and Arlen $(1990,1992)$ present models in which both the injurer and the victim incur accident losses. Shavell (1982) introduces risk aversion into the basic unilateral accident model. Shavell (1986) examines the judgment-proof problem. For additional complexities that have been introduced in the literature, see generally Shavell (1987) and Miceli (1997). 
agent faces ambiguity $(\delta>0)$. Now a preference for urn 1 in gamble A implies $\frac{1}{2} u(100)+\frac{1}{2} u(0)>[\delta \alpha+(1-\delta)(1-p)] u(0)+[\delta(1-\alpha)+$ $(1-\delta) p] u(100)$, or $\frac{1}{2}>\delta(1-\alpha)+(1-\delta) p=\mu(p)$, and a preference for urn 1 in gamble B implies $\frac{1}{2} u(0)+\frac{1}{2} u(100)>[\delta \alpha+(1-\delta) p] u(0)+[\delta(1-\alpha)+$ $(1-\delta)(1-p)] u(100)$, or $\frac{1}{2}>\delta(1-\alpha)+(1-\delta)(1-p)=\mu(1-p)$. Combining these conditions gives $\mu(p)+\mu(1-p)<1$, which is consistent with the convexity of $\mu$.

2.3.2. Neoadditive Capacities. A neoadditive capacity is a probability weighting function. In particular, it is a simple version of the familiar inverse-S-shaped probability weighting function from cumulative prospect theory (Tversky and Kahneman 1992). Empirical studies indicate that individuals tend to overweight low probabilities and underweight high probabilities, with the most pronounced misweighting near the extremes of the probability scale (see Gonzalez and Wu 1999). This systematic distortion of probabilities implies an inverse-S-shaped probability weighting function. There is overwhelming evidence from parametric and nonparametric studies for the inverse-S shape (see Wakker 2001). A standard nonlinear specification of an inverse-S-shaped probability weighting function is depicted in Figure 1 (dashed curve). A neoadditive capacity, also depicted in Figure 1 (solid line), is a simple linear specification.

Under Choquet expected utility with a neoadditive capacity, an agent's preferences are represented by a weighted sum of the minimum utility, the maximum utility, and the expected utility. There is experimental evidence that preferences have this form. Lopes (1987) proposes a theory for risky choice that integrates two factors: a dispositional tendency to seek either security or potential and a situational aspiration level. Under Lopes's theory, the security/potential factor reflects how a person weights the worst and best outcomes, while the aspiration level reflects an assessment of what outcome is reasonable to expect under the circumstances. On the basis of her theory, Lopes makes predictions about preferences over lotteries. She then presents experimental evidence consistent with her predictions.

2.3.3. Ambiguity, Optimism, and Pessimism. An advantage of representing beliefs with a neoadditive capacity is that it allows me to define concrete notions of ambiguity, optimism, and pessimism. Ambiguity corresponds to an agent's lack of confidence in his belief about the probability of uncertain events. Optimism and pessimism are defined according to the weights applied to extreme outcomes. Optimism means 


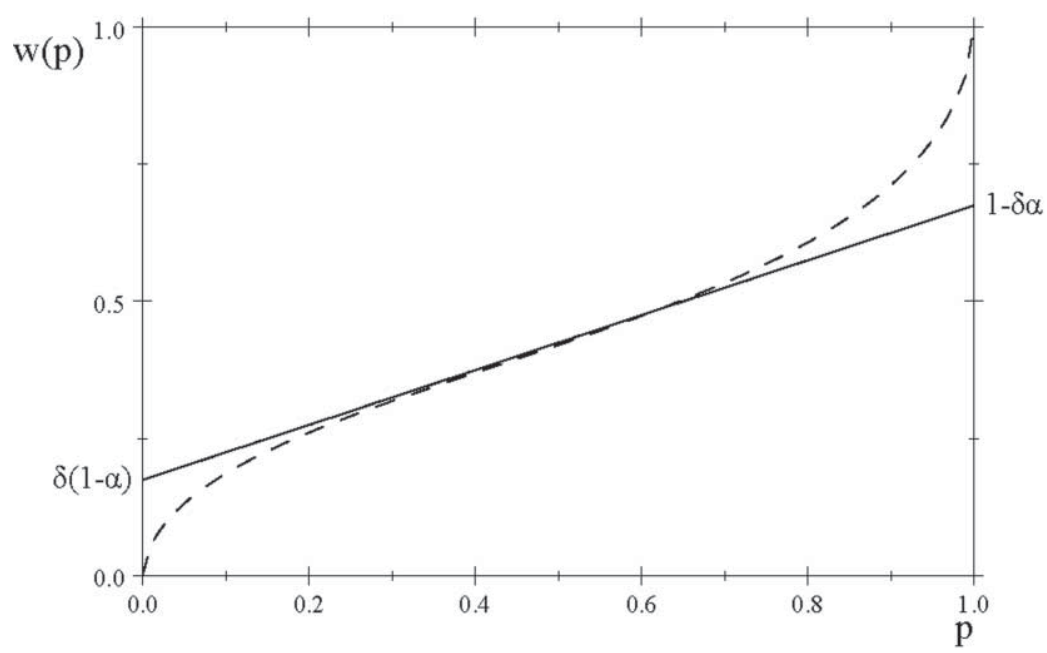

Figure 1. Neoadditive capacity as a linear inverse-S-shaped probability weighting function

the weight applied to the best outcome exceeds the probability of the best outcome, and pessimism means the weight applied to the worst outcome exceeds the probability of the worst outcome. ${ }^{25}$

The use of the terms "optimism" and "pessimism" in the present framework is consistent with their use within an expected utility framework, in which optimism means the agent's subjective probability of a favorable (unfavorable) outcome is greater (less) than the objective probability of that outcome and pessimism means the agent's subjective probability of a favorable (unfavorable) outcome is less (greater) than the objective probability of that outcome (see, for example, Posner 2003; Bar-Gill 2006). In both frameworks, optimism and pessimism correspond to "incorrect" decision weights resulting from misweighted or misperceived probabilities. The key distinction lies in their interpretation. In the present framework, optimism and pessimism properly may

25. In general, the agent may overweight both the best and worst outcomes and underweight nonextreme outcomes. In the present model, however, in which there are only two outcomes, the injurer overweights either the accident outcome or the no-accident outcome but not both. A disadvantage of a neoadditive capacity is that it allows only the best and worst outcomes to be overweighted. A more general type of capacity, called a JP capacity, allows a number of good and bad outcomes to be overweighted (see Eichberger and Kelsey 2006). However, when there are only two outcomes, as in the present model, a JP capacity is isomorphic to a neoadditive capacity. 
be interpreted as attitudes toward or reactions to ambiguity. Specifically, optimism corresponds to a concave (superadditive) capacity that reflects ambiguity loving, while pessimism corresponds to a convex (subadditive) capacity that reflects ambiguity aversion (see Schmeidler 1989; Wakker 2001). However, as illustrated above, attitudes toward ambiguity cannot be captured within an expected utility framework because beliefs are represented with probabilities. In the expected utility framework, therefore, optimism and pessimism may not be interpreted as reactions to ambiguity.

Another advantage of a neoadditive capacity is that it parameterizes ambiguity, optimism, and pessimism. In the model, I interpret $\delta$ as the degree of ambiguity because it is the complement of the injurer's degree of confidence in $\pi$. I interpret $\alpha$ and $1-\alpha$ as the injurer's degrees of pessimism and optimism because they determine the respective weights assigned to the accident and no-accident outcomes.

I can further motivate interpreting $\delta, \alpha$, and $1-\alpha$ as the injurer's degrees of ambiguity, pessimism, and optimism by reference to a multiple-priors version of the model, in which the injurer's beliefs about accident risk are represented by a set of probabilities "centered" around $\pi$ (see Eichberger and Kelsey 2006; Chateauneuf, Eichberger, and Grant, forthcoming). It can be shown that equation (1) is equivalent to

$$
V_{\pi}(c)=\alpha \min _{p \in \mathcal{P}(\pi)} E_{p}(c)+(1-\alpha) \max _{p \in \mathcal{P}(\pi)} E_{p}(c),
$$

where $\mathcal{P}(\pi)=\{p \in[0,1]:(1-\delta) \pi \leq p \leq \delta+(1-\delta) \pi\}$ represents the set of accident probabilities $p$ the injurer considers possible and $E_{p}(c)$ denotes the expected utility with respect to $p$ of exercising level of care $c$ given the applicable liability rule (see Eichberger and Kelsey 2006). In this version, I interpret $\delta$ as the degree of ambiguity because it determines and measures the size of the set $\mathcal{P}(\pi)$. If $\delta=0$, the injurer unambiguously believes the probability of an accident is $\pi$ (that is, $\mathcal{P}(\pi)=\{\pi\}$ ). As $\delta \rightarrow 1$, the injurer considers an increasing range of accident probabilities to be possible. For $\delta=1$, he believes all probabilities are possible (that is, $\mathcal{P}(\pi)=[0,1])$. I interpret $\alpha$ and $1-\alpha$ as the injurer's degrees of pessimism and optimism because they correspond to the respective weights the injurer applies to the minimum and maximum expected utility over the set $\mathcal{P}(\pi)$. Stated another way, I interpret $\alpha$ and $1-\alpha$ as degrees of pessimism and optimism because they reflect the respective degrees to which the injurer evaluates the expected utility of exercising 
level of care $c$ by the lowest and highest accident probabilities he considers possible.

2.3.4. Relationship to Other Models. Choquet expected utility with a neoadditive capacity $\mu$ based on a probability distribution $p$ contains as special cases or is mathematically equivalent to several alternative models of decision making under uncertainty, including but not limited to (1) subjective expected utility, where $p$ represents the agent's beliefs, if $\delta=0$ and $\alpha \in[0,1],(2) \alpha$-maxmin expected utility with multiple priors (Ghirardato, Maccheroni, and Marinacci 2004), where the set of priors is $\mathcal{D}=\{q \in \Delta: q \geq(1-\delta) p\}$ (see Eichberger and Kelsey 2006; Chateauneuf, Eichberger, and Grant, forthcoming), (3) rank-dependent expected utility with probability weighting function $\omega(p)=\mu(p)$ (see Wakker 1990), and (4) cumulative prospect theory with probability weighting function $\omega(p)=\mu(p)$ and symmetric treatment of gains and losses (see Tversky and Wakker 1995). ${ }^{26}$

\section{RESULTS}

In order to establish the benchmark for comparison, I first derive the socially optimal level of care and state the results of the model in the absence of ambiguity, which correspond to the standard results of the basic unilateral accident model. I then derive the results of the model in the presence of ambiguity.

\subsection{Socially Optimal Level of Care}

In conformity with Shavell (1987) and others, I assume the social goal is to minimize total accident $\operatorname{costs} c+L(c)$. That is, I assume the socially optimal level of care $c^{*}$ solves

$$
\min _{c \geq 0} c+L(c)
$$

Assuming $c^{*}$ is positive, it is implicitly defined by the first-order condition

$$
-L^{\prime}\left(c^{*}\right)=1
$$

Equation (5) requires that the marginal reduction in expected accident losses-that is, the marginal benefit of care-equals the marginal cost

26. Additional relationships to other well-known models are identified in Appendix A. 
of care. Note that equation (5) defines the socially optimal level of care whether accident losses are fixed or variable. ${ }^{27}$

\subsection{Results without Ambiguity}

As noted above, in the absence of ambiguity $(\delta=0)$, the model reduces to the basic unilateral accident model. In both cases of accident losses, therefore, the results of the model without ambiguity correspond to the standard results of the basic unilateral accident model, which may be summarized as follows (Shavell 1987).

Proposition 1. Under a rule of no liability, the injurer will exercise no care. Under strict liability, the injurer will exercise the socially optimal level of care. Under a negligence rule with the standard of due care set equal to the socially optimal level of care, the injurer will exercise the socially optimal level of care.

Proof. Under each liability rule, the injurer's problem is to choose the level of care that maximizes the expected outcome of engaging in his activity. Because the injurer is risk neutral and his payoff $k$ is fixed, the injurer's problem is equivalent to minimizing his expected costs, which equal his cost of care plus his expected liability. Specifically, under a rule of no liability, the injurer's problem is

$$
\min _{c \geq 0} c
$$

and the injurer will choose $c^{\mathrm{NL}}=0<c^{*}$. Under strict liability, the injurer's problem is

$$
\min _{c \geq 0} c+L(c)
$$

Assuming the solution is positive, it is implicitly defined by the condition $-L^{\prime}\left(c^{\mathrm{SL}}\right)=1$. Together with equation (5), this implies the injurer will

27. In contrast to the standard model, in the present model minimizing total accident costs is not necessarily equivalent to maximizing the sum of the utilities of the injurer and the victim. They do not coincide if the injurer faces ambiguity about accident risk and he is either optimistic or pessimistic (that is, if $\delta>0$ and $\alpha \neq \pi$ ). However, $c^{*}$ is the level of care that would be chosen by a rational social planner as part of a Pareto-optimal allocation (see Appendix B). Accordingly, I maintain that minimizing total accident costs is the appropriate social goal. Note that Posner (2003), Eide (2005), and Bigus (2006) take the same view. But compare Eide (2007). 
choose $c^{\mathrm{SL}}=c^{*}$ because $L^{\prime \prime}(c)>0$. Under a negligence rule, the injurer's problem is

$$
\min _{c \geq 0} \begin{cases}c & \text { if } c \geq \bar{c} \\ c+L(c) & \text { if } c<\bar{c}\end{cases}
$$

If the court sets the standard of due care equal to the socially optimal level of care $\left(\bar{c}=c^{*}\right)$, then the injurer will choose $c^{\mathrm{N}}=c^{*}$ because $c^{*}=\operatorname{argmin}_{c \geq c^{*}}$, and, given my assumptions, $c^{*}<c^{*}+L\left(c^{*}\right) \leq \min \{c+$ $\left.L(c): c \in\left[0, c^{*}\right)\right\}$. Q.E.D.

It is obvious why the injurer will exercise no care under a rule of no liability. Under strict liability, the injurer's marginal benefit of care equals the social marginal benefit of care. Consequently, strict liability induces the injurer to take optimal care. The reason the injurer takes optimal care under a negligence rule with the standard of due care set equal to the socially optimal level of care is twofold. First, the injurer will not exercise too much care because he faces no liability if his level of care is at or above the socially optimal level of care. Second, the injurer will not exercise too little care because he faces strictly liability if his level of care is below the socially optimal level of care, and strict liability induces him to exercise the socially optimal level of care.

The results of proposition 1 are illustrated by Figure 2, which is a variation of a classic diagram from the tort law and economics literature (see, for example, Shavell 1987; Miceli 1997). The curve $c+L(c)$ represents the injurer's expected cost schedule under strict liability, while the thick portion of $c+L(c)$ plus the line segment $c$ represent the injurer's expected cost schedule under a negligence rule with the standard of due care set equal to the socially optimal level of care. As shown in Figure 2 , under each liability rule the injurer's expected cost schedule attains its minimum at the socially optimal level of care, $c^{*}$.

\subsection{Results under Ambiguity}

I now consider the injurer's behavior under ambiguity $(\delta>0)$. I analyze separately the cases of fixed accident losses and variable accident losses. In the case of fixed accident losses, certain of the comparative statics results will depend on a property of $\pi(c)$ that I shall call local convexity and measure by $\rho_{\pi}(c) \equiv-\left[\pi^{\prime \prime}(c) / \pi^{\prime}(c)\right]$. The term $\rho_{\pi}(c)$ may be viewed as a measure of the local convexity of $\pi(c)$ because, loosely speaking, it 


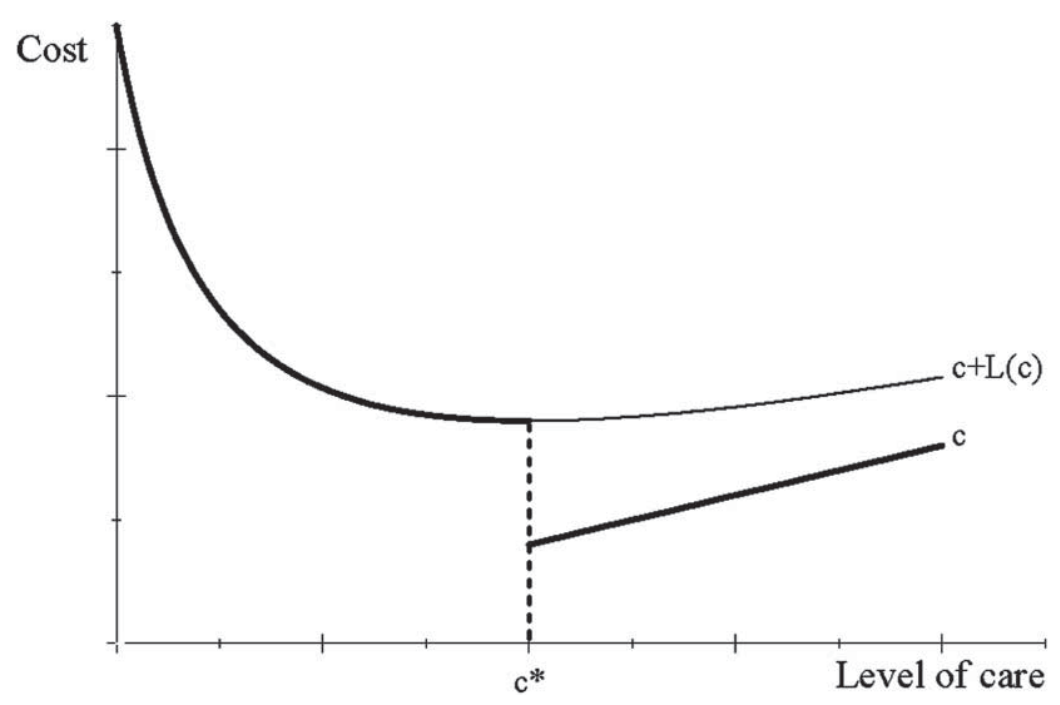

Figure 2. Efficient care under strict liability and negligence

measures the degree of curvature of $\pi$ at $c .{ }^{28}$ I shall say that $\pi(c)$ exhibits increasing (decreasing) local convexity if $\rho_{\pi}(c)$ is an increasing (decreasing) function of $c$.

\subsubsection{Fixed Accident Losses}

No Liability. Under a rule of no liability, whether or not an accident occurs, the outcome for the injurer is the same: $m(c)=M(c)=k-c$. It follows from equation (1) that the injurer's problem is $\max _{c \geq 0} k-c$, which is equivalent to equation (6). Hence, he will choose $c^{\mathrm{NL}}=0<$ $c^{*}$. That is, the injurer will exercise no care.

Strict Liability. Under strict liability, the worst outcome is $m(c)=k-$ $c-l$ and the best outcome is $M(c)=k-c$. Accordingly, by equation (1) the injurer's problem is

$$
\begin{gathered}
\max _{c \geq 0} \delta \alpha(k-c-l)+\delta(1-\alpha)(k-c) \\
+(1-\delta)\{\pi(c)(k-c-l)+[1-\pi(c)](k-c)\},
\end{gathered}
$$

28. This view of $\rho_{\pi}(c)$ is motivated by the standard interpretation of the Arrow-Pratt coefficient of absolute risk aversion $r_{u}(x)=-\left[u^{\prime \prime}(x) / u^{\prime}(x)\right]$ as a measure of the curvature of the utility function $u$ at $x$ (see, for example, Mas-Colell, Whinston, and Green 1995, p. 190). 
which is equivalent to

$$
\min _{c \geq 0} c+\delta \alpha l+(1-\delta) L(c)
$$

Assuming that $\delta<1$ and the solution to equation (10) is positive, it is implicitly defined by the first-order condition

$$
-L^{\prime}\left(c^{\mathrm{SL}}\right)=\frac{1}{1-\delta}
$$

Equation (11) implies the following results.

Proposition 2. In the case of fixed accident losses, the level of care exercised by the injurer under strict liability will be less than the socially optimal level of care. In addition, the injurer's level of care decreases with the degree of ambiguity. As a result, the difference between the socially optimal level of care and the injurer's level of care increases with the degree of ambiguity. Furthermore, while the injurer's level of care increases with the magnitude of accident losses, so does the difference between the socially optimal level of care and the injurer's level of care if $\pi(c)$ exhibits decreasing local convexity.

Proof. See Appendix B.

The intuition behind proposition 2 is straightforward. If equation (11) is rewritten as $-(1-\delta) \pi^{\prime}\left(c^{\mathrm{SL}}\right) l=1$, we see that ambiguity leads the injurer to discount the marginal benefit of care. As a result, the injurer will exercise too little care. An increase in the degree of ambiguity increases the ambiguity discount but does not affect the marginal benefit of care. Consequently, the injurer reduces his level of care further below the unchanged socially optimal level of care. On the other hand, an increase in the magnitude of accident losses increases the marginal benefit of care but does not affect the ambiguity discount. Both the injurer's level of care and the socially optimal level of care increase in response to the increase in the marginal benefit of care. However, if the marginal benefit of care decreases too rapidly with the level of care, the ambiguity discount leads the injurer to increase his level of care by less than the increase in the socially optimal level of care.

Negligence. Under a negligence rule with the standard of due care set equal to the socially optimal level of care $\left(\bar{c}=c^{*}\right)$, the injurer's prob- 
450 / THE JOURNAL OF LEGAL STUdiES / VOLUME 36 (2) / JUNE 2007

lem is

$$
\min _{c \geq 0} \begin{cases}c & \text { if } c \geq c^{*} \\ c+\delta \alpha l+(1-\delta) L(c) & \text { if } c<c^{*}\end{cases}
$$

Note that $c^{*}=\operatorname{argmin}_{c \geq c^{*}} \mathcal{C}$ and that $c^{\mathrm{SL}}=\operatorname{argmin}_{c \in\left[0, c^{*}\right)} c+\delta \alpha l+(1-$ $\delta) L(c)$. It follows that the injurer will choose

$$
c^{\mathrm{N}}= \begin{cases}c^{*} & \text { if } c^{*} \leq F\left(c^{\mathrm{SL}}\right) \\ c^{\mathrm{SL}}<c^{*} & \text { if } c^{*}>F\left(c^{\mathrm{SL}}\right),\end{cases}
$$

where $F\left(c^{\mathrm{SL}}\right) \equiv c^{\mathrm{SL}}+\delta \alpha l+(1-\delta) L\left(c^{\mathrm{SL}}\right)$. Note that $F\left(c^{\mathrm{SL}}\right)$ is the injurer's expected costs if he is negligent. Therefore, it is the expected benefit of exercising due care. Equation (13) implies the following results.

Proposition 3. In the case of fixed accident losses, the injurer's level of care under a negligence rule with the standard of due care set equal to the socially optimal level of care will be less than or equal to the socially optimal level of care. The likelihood that the injurer will exercise too little care (1) increases with the degree of ambiguity if he is optimistic and decreases therewith if he is pessimistic, (2) increases with his degree of optimism and decreases with his degree of pessimism, and (3) increases with the magnitude of accident losses if $F\left(c^{\mathrm{SL}}\right)-c^{\mathrm{SL}}<1 / \rho_{\pi}\left(c^{*}\right)$ and decreases therewith if the reverse inequality holds.

Proof. See Appendix B.

The results of proposition 3 may be understood as follows. With or without ambiguity, the injurer will never exercise too much care under a negligence rule with the standard of due care set equal to the socially optimal level of care because he can avoid liability simply by exercising due care. In the presence of ambiguity, however, the cost of exercising due care, $c^{*}$, may exceed the expected benefit, $F\left(c^{\mathrm{SL}}\right)$, in which case the injurer will exercise too little care. The likelihood that the injurer will exercise too little care increases with the difference $c^{*}-F\left(c^{\mathrm{SL}}\right)$. Because ambiguity affects the expected benefit, but not the cost, of exercising due care, variation in the likelihood that the injurer will exercise too little care in response to changes in ambiguity or the injurer's attitude toward ambiguity results from variation in the expected benefit of exercising due care. The expected benefit of exercising due care increases with ambiguity if the injurer is pessimistic because he reacts by further overweighting the accident outcome; it decreases with ambiguity if the injurer is optimistic because he reacts by further underweighting the accident outcome. Similarly, the expected benefit of exercising due care increases as the injurer 
becomes relatively more pessimistic because he reacts by increasing the weight on the accident outcome and decreases as he becomes relatively more optimistic because he reacts by decreasing the weight on the accident outcome. An increase in the magnitude of accident losses increases both the cost and the expected benefit of exercising due care. Whether the cost or the expected benefit increases at a faster rate depends on the relationship between $F\left(c^{\mathrm{SL}}\right)-c^{\mathrm{SL}}$, the injurer's expected liability if he is negligent, and $1 / \rho_{\pi}\left(c^{*}\right)$, the inverse local convexity of $\pi(c)$ at $c^{*}$. When $F\left(c^{\mathrm{SL}}\right)-c^{\mathrm{SL}}<$ $1 / \rho_{\pi}\left(c^{*}\right)$, the cost of exercising due care increases more rapidly than the expected benefit, and when $F\left(c^{\mathrm{SL}}\right)-c^{\mathrm{SL}}>1 / \rho_{\pi}\left(c^{*}\right)$, the expected benefit increases more rapidly than the cost. This is because $F\left(c^{\mathrm{SL}}\right)-c^{\mathrm{SL}}$ and $1 / \rho_{\pi}\left(c^{*}\right)$ are in the same proportion as the marginal expected benefit and the marginal cost of exercising due care. ${ }^{29}$

\subsubsection{Variable Accident Losses}

No Liability. The nature of accident losses is irrelevant under a rule of no liability. Thus, the injurer's problem with variable accident losses is identical to his problem with fixed accident losses, and the injurer will exercise no care-that is, $c^{\mathrm{NL}}=0<c^{*}$.

Strict Liability. Under strict liability, the injurer's problem is

$$
\max _{c \geq 0} c+\delta \alpha l(c)+(1-\delta) L(c)
$$

Assuming that $\delta<1$ and the solution to equation (14) is positive, it is implicitly defined by the first-order condition

$$
-L^{\prime}\left(c^{\mathrm{SL}}\right)=\frac{1+\delta \alpha l^{\prime}\left(c^{\mathrm{SL}}\right)}{1-\delta}
$$

Assuming that $\alpha>0$, equations (5) and (15) imply $-L^{\prime}\left(c^{\mathrm{SL}}\right) \gtreqless-L^{\prime}\left(c^{*}\right)$ as $-l^{\prime}\left(c^{\mathrm{SL}}\right) \lesseqgtr \frac{1}{\alpha}$, which in turn implies

$$
c^{\mathrm{SL}} \lesseqgtr c^{*} \quad \text { as } \quad-l^{\prime}\left(c^{\mathrm{SL}}\right) \lesseqgtr \frac{1}{\alpha}
$$

because $L^{\prime \prime}(c)>0 .{ }^{30}$ Equations (15) and (16) imply the following results.

Proposition 4. In the case of variable accident losses, the injurer's level of care under strict liability may be less than, equal to, or greater than the socially optimal level of care, where equality is a borderline case.

29. To see this, note that $\partial F\left(c^{\mathrm{SL}}\right) / \partial l=\left[F\left(c^{\mathrm{SL}}\right)-c^{\mathrm{SL}}\right] / l$ and $\partial c^{*} / \partial l=1 / \rho_{\pi}\left(c^{*}\right) l$.

30. Note that equation (15) requires $-l^{\prime}\left(c^{\mathrm{SL}}\right)<1 / \delta \alpha$ because $L^{\prime}(c)<0$. 
The injurer's level of care decreases with his degree of optimism and increases with his degree of pessimism. As a result, the likelihood that the injurer will exercise too little care increases with his degree of optimism and decreases with his degree of pessimism. Conversely, the likelihood that the injurer will exercise too much care decreases with his degree of optimism and increases with his degree of pessimism. The injurer's level of care decreases with the degree of ambiguity if he is optimistic or if he is pessimistic and $\alpha<L^{\prime}\left(c^{\mathrm{SL}}\right) / l^{\prime}\left(c^{\mathrm{SL}}\right)$ and increases therewith if he is pessimistic and $\alpha>L^{\prime}\left(c^{\mathrm{SL}}\right) / l^{\prime}\left(c^{\mathrm{SL}}\right)$. Accordingly, the likelihood that the injurer will exercise too little care increases with the degree of ambiguity if he is optimistic or if he is pessimistic and $\alpha<L^{\prime}\left(c^{\mathrm{SL}}\right) / l^{\prime}\left(c^{\mathrm{SL}}\right)$ and decreases therewith if he is pessimistic and $\alpha>L^{\prime}\left(c^{\mathrm{SL}}\right) / l^{\prime}\left(c^{\mathrm{SL}}\right)$. Conversely, the likelihood that the injurer will exercise too much care decreases with the degree of ambiguity if he is optimistic or if he is pessimistic and $\alpha<L^{\prime}\left(c^{\mathrm{SL}}\right) / l^{\prime}\left(c^{\mathrm{SL}}\right)$ and increases therewith if he is pessimistic and $\alpha>L^{\prime}\left(c^{\mathrm{SL}}\right) / l^{\prime}\left(c^{\mathrm{SL}}\right)$.

Proof. See Appendix B.

To understand why ambiguity may lead the injurer to exercise too little or too much care under strict liability in the case of variable accident losses, rewrite equation (15) as $-(1-\delta) L^{\prime}\left(c^{\mathrm{SL}}\right)-\delta \alpha l^{\prime}\left(c^{\mathrm{SL}}\right)=1$. We see that while ambiguity leads the injurer to discount the benefit from a marginal reduction in expected accident losses, it also leads the injurer to benefit from a marginal reduction in the magnitude of accident losses per se, which latter benefit increases with the injurer's degree of pessimism. If the latter benefit is sufficiently large and the injurer is sufficiently pessimistic, he will find it worthwhile to increase his level of care above the socially optimal level of care, notwithstanding the ambiguity discount on expected accident losses. Otherwise, as in the case of fixed accident losses, the ambiguity discount will cause the injurer to exercise too little care.

The comparative statics results on optimism, pessimism, and ambiguity are consistent with the corresponding results of propositions 3 and 5 and form part of a general finding that the injurer's level of care decreases with his degree of optimism, increases with his degree of pessimism, and decreases or increases with the degree of ambiguity depending on whether he is optimistic or pessimistic, respectively. ${ }^{31}$ This finding agrees with my

31. It should be noted that, unlike in propositions 3 and 5, the comparative statics result with respect to ambiguity in proposition 4 does not match the general finding precisely. However, it deviates only when $\pi\left(c^{\mathrm{SL}}\right)<\alpha<L^{\prime}\left(c^{\mathrm{SL}}\right) / l^{\prime}\left(c^{\mathrm{SL}}\right)=\pi\left(c^{\mathrm{SL}}\right)+\left[\pi^{\prime}\left(c^{\mathrm{SL}}\right) /\right.$ $\left.l^{\prime}\left(c^{\mathrm{SL}}\right)\right] l\left(c^{\mathrm{SL}}\right)$, and this range will be narrow provided that the marginal reduction in the magnitude of accident losses is sufficiently greater than the marginal reduction in the 
basic intuition, for it seems natural that if and to the extent the injurer reacts to ambiguity in an optimistic way by overweighing the no-accident outcome, he would tend to reduce his level of care, and if and to the extent the injurer reacts to ambiguity in a pessimistic way by overweighting the accident outcome, he would tend to increase his level of care. It is also consistent with the general thinking of legal scholars (see Posner 2003).

Negligence. Under a negligence rule with the standard of due care set equal to the socially optimal level of care, the injurer's problem is

$$
\min _{c \geq 0} \begin{cases}c & \text { if } c \geq c^{*} \\ c+\delta \alpha l(c)+(1-\delta) L(c) & \text { if } c<c^{*}\end{cases}
$$

If $-l^{\prime}\left(c^{\mathrm{SL}}\right) \geq \frac{1}{\alpha}$, then the injurer will choose $c^{\mathrm{N}}=c^{*} \leq c^{\mathrm{SL}}$ because $c^{*}=$ $\operatorname{argmin}_{c \geq c^{*}} c$ and $c^{*}<c^{*}+\delta \alpha l\left(c^{*}\right)+(1-\delta) L\left(c^{*}\right) \leq \min \{c+\delta \alpha l(c)+(1-$ $\left.\delta) L(c): c \in\left[0, c^{*}\right)\right\}$. If $-l^{\prime}\left(c^{\mathrm{SL}}\right)<\frac{1}{\alpha}$, then $c^{\mathrm{SL}}<c^{*}$, and the injurer will choose

$$
c^{\mathrm{N}}= \begin{cases}c^{*} & \text { if } c^{*} \leq G\left(c^{\mathrm{SL}}\right) \\ c^{\mathrm{SL}}<c^{*} & \text { if } c^{*}>G\left(c^{\mathrm{SL}}\right),\end{cases}
$$

where $G\left(c^{\mathrm{SL}}\right) \equiv c^{\mathrm{SL}}+\delta \alpha l\left(c^{\mathrm{SL}}\right)+(1-\delta) L\left(c^{\mathrm{SL}}\right)$, because $c^{*}=\operatorname{argmin}_{c \geq c^{*}} c$ and $c^{\mathrm{SL}}=\operatorname{argmin}_{c \in\left[0, c^{*}\right)} c+\delta \alpha l(c)+(1-\delta) L(c)$. The injurer's decision rules imply the following results.

Proposition 5. In the case of variable accident losses, the injurer's level of care under a negligence rule with the standard of due care set equal to the socially optimal level of care will be less than or equal to the socially optimal level of care. The likelihood that the injurer will exercise too little care (1) increases with his degree of optimism and decreases with his degree of pessimism and (2) increases with the degree of ambiguity if he is optimistic and decreases therewith if he is pessimistic.

Proof. See Appendix B.

The results of proposition 5 follow from previous results. The injurer may exercise too little care under negligence for the same reason he may exercise too little care under strict liability: he discounts the marginal benefit of care. The injurer will never exercise too much care under negligence because, as noted above, he can avoid liability by exercising the socially optimal level of care. The comparative statics results on optimism,

probability of an accident at $c^{\text {SL }}$ or that the magnitude of accident losses given $c^{\text {SL }}$ is sufficiently small, either or both of which it seems reasonable to assume. 
454 / THE JOURnal OF LEGAL Studies / VOLUME 36 (2) / JUNE 2007

pessimism, and ambiguity support the finding that, in general, the injurer's level of care decreases with optimism, increases with pessimism, and decreases or increases with ambiguity depending on whether he is optimistic or pessimistic, respectively.

\section{NUMERICAL EXAMPLE}

This section develops a simple numerical example in order to illustrate the results of the model. Throughout the example, I assume that

1. the probability of an accident is $\pi(c)=1 /(1+c)$;

2. the degree of ambiguity may be zero, low, or high: $\delta \in\{0$, 9/25, 21/25\}; and

3. the injurer's degree of pessimism may be low or high: $\alpha \in$ $\{1 / 50,39 / 50\}$.

Note that $\pi(c)$ is strictly decreasing, strictly convex, and exhibits decreasing local convexity. ${ }^{32}$ In addition, it turns out that $\pi(c) \in$ $(1 / 50,39 / 50)$ for each level of care the injurer may exercise. Accordingly, the injurer is optimistic when his degree of pessimism is low and pessimistic when his degree of pessimism is high.

\subsection{Fixed Accident Losses}

To begin, suppose accident losses are fixed and their magnitude may be low or high: $l \in\{25,36\}$. Given our assumptions, the socially optimal level of care is $c^{*}=\sqrt{ } l-1$. Thus, $c^{*}=4$ when accident losses are low and $c^{*}=5$ when accident losses are high.

4.1.1. Strict Liability. Under strict liability, the injurer's level of care is $c^{\mathrm{SL}}=\sqrt{(1-\delta) l}-1$. Note that the injurer's level of care does not depend on his degree of pessimism, $\alpha$. Table 1 sets forth the socially optimal level of care, $c^{*}$, and the injurer's level of care, $c^{\mathrm{SL}}$, for each possible pair $(l, \delta)$. From Table 1 we can see the following results.

1. The injurer will take optimal care in the absence of ambiguity, but in the presence of ambiguity he will take too little care.

2. Increasing ambiguity progressively reduces the injurer's level of care below the socially optimal level of care. In particular, as the degree of ambiguity increases from zero to low to high, the injurer's level of

32. To see this, note that $\pi^{\prime}(c)=-1 /(1+c)^{2}<0, \pi^{\prime \prime}(c)=2 /(1+c)^{3}>0$, and $\rho_{\pi}^{\prime}(c)=$ $-2 /(1+c)^{2}<0$. 
Table 1. Levels of Care under Strict Liability with Fixed Accident Losses

\begin{tabular}{lll}
\hline$(l, \delta)$ & $c^{*}$ & $c^{\mathrm{SL}}$ \\
\hline$(25,0)$ & 4 & 4 \\
$(25,9 / 25)$ & 4 & 3 \\
$(25,21 / 25)$ & 4 & 1 \\
$(36,0)$ & 5 & 5 \\
$(36,9 / 25)$ & 5 & 3.8 \\
$(36,21 / 25)$ & 5 & 1.4 \\
\hline
\end{tabular}

care falls from 4 to 3 to 1 if accident losses are low and from 5 to 3.8 to 1.4 if accident losses are high.

3. While the injurer's level of care increases in response to an increase in the magnitude of accident losses, the gap between the injurer's level of care and the socially optimal level of care increases as well. Specifically, if accident losses increase from low to high, the socially optimal level of care increases by 1 while the injurer's level of care increases only by .8 if ambiguity is low and by .4 if ambiguity is high.

Each of these results is consistent with proposition 2. Figure 3 illustrates the second result assuming low accident costs and a high degree of pessimism. Figure 4 illustrates the third result assuming a low degree of ambiguity and a high degree of pessimism.

4.1.2. Negligence. Under a negligence rule with the standard of due care set equal to the socially optimal level of care, the injurer will exercise due care if the cost, $c^{*}$, does not exceed the expected benefit, $F\left(c^{\mathrm{SL}}\right) \equiv$ $c^{\mathrm{SL}}+\delta \alpha l+(1-\delta) L\left(c^{\mathrm{SL}}\right)$; otherwise he will exercise $c^{\mathrm{SL}}$. Table 2 sets forth the relevant cost-benefit calculations and specifies the injurer's level of care, $c^{\mathrm{N}}$, for each possible triple $(l, \delta, \alpha)$. From Table 2 we can see the following results.

1. The injurer will take optimal care in the absence of ambiguity if ambiguity is low or if he is pessimistic. The injurer will exercise too little care only when ambiguity is high and he is optimistic.

2. Increasing ambiguity progressively reduces the expected benefit of exercising due care if the injurer is optimistic and progressively increases it if he is pessimistic. In particular, if the injurer is optimistic, as the degree of ambiguity increases from zero to low to high, the expected benefit of exercising due care falls from 9 to 7.18 to 3.42 if accident losses are low and from 11 to 8.86 to 4.40 if accident losses are high. If the injurer is pessimistic, however, as the degree of ambiguity increases 
456 / THE JOURNAL OF LEGAL STUdies / VOLUME 36 (2) / JUNE 2007

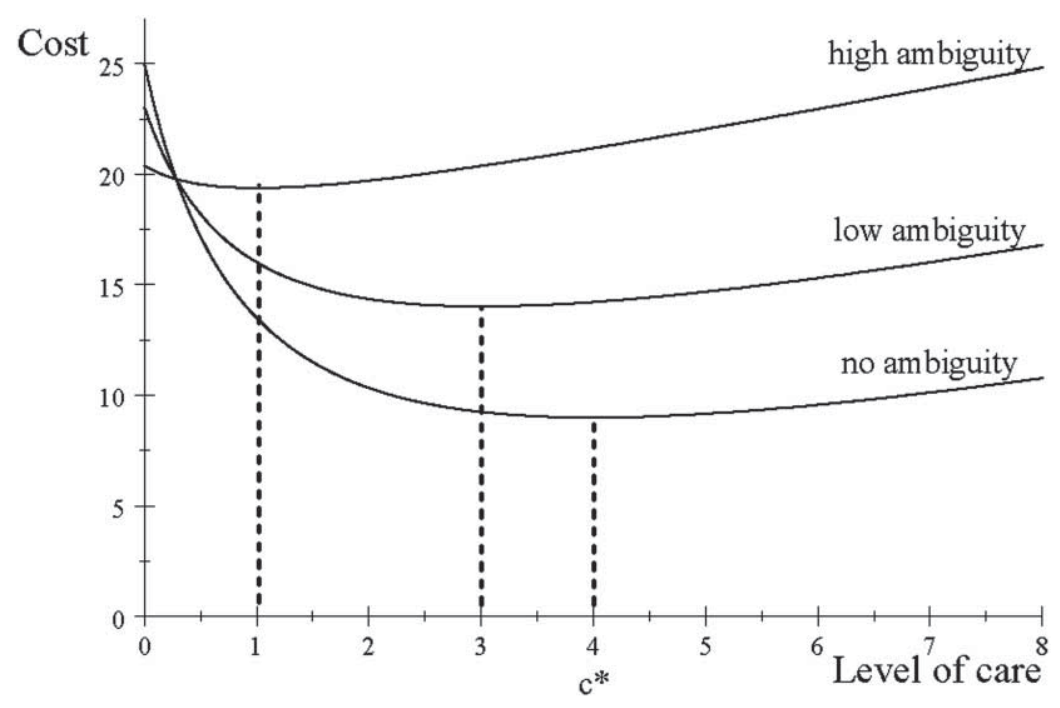

Figure 3. Effect on care of increasing ambiguity under strict liability with fixed accident losses.

from zero to low to high, the expected benefit of exercising due care rises from 9 to 14.02 to 19.38 if accident losses are low and from 11 to 18.71 to 27.39 if accident losses are high.

3. In the presence of ambiguity, the expected benefit of exercising due care increases with the injurer's degree of pessimism. Specifically, when ambiguity is low, as the injurer's degree of pessimism increases from low to high, the expected benefit of exercising due care rises from 7.18 to 14.02 if accident losses are low and from 8.86 to 18.71 if accident losses are high. When ambiguity is high, as the injurer's degree of pessimism increases from low to high, the expected benefit of exercising due care leaps from 3.42 to 19.38 if accident losses are low and from 4.40 to 27.39 if accident losses are high.

4. While both the cost and the expected benefit of exercising due care increase in response to an increase in the magnitude of accident losses, the gap between them increases as well.

All four results are consistent with proposition 3. Note that the second and third results are consistent because the likelihood that the injurer will exercise too little care varies inversely with the expected benefit of exercising due care in response to changes in ambiguity or the injurer's 


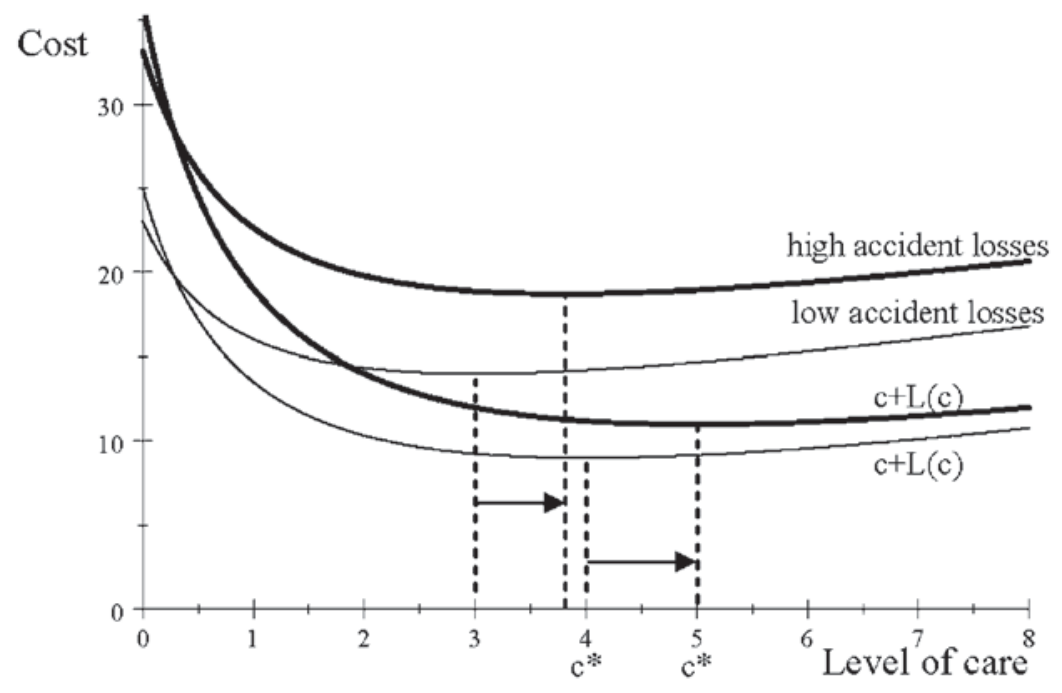

Figure 4. Effect on care of increasing fixed accident losses under strict liability

attitude toward ambiguity. To see that the fourth result is consistent, note that (1) when ambiguity is high and the injurer is optimistic, $1 / \rho_{\pi}\left(c^{*}=4\right)=2.5>2.42=F\left(c^{\mathrm{SL}}\right)-c^{\mathrm{SL}}$, and the expected benefit of exercising due care increases by less than the cost when the magnitude of accident losses increases from low to high and (2) in all other cases, $F\left(c^{\mathrm{SL}}\right)-c^{\mathrm{SL}}>2.5=1 / \rho_{\pi}\left(c^{*}=4\right)$, and the expected benefit of exercising due care increases by more than the cost when the magnitude of accident losses increases from low to high. Figure 5 illustrates how an optimistic injurer will take optimal care in the absence of ambiguity or if ambiguity is low but will exercise too little care when ambiguity is high. It assumes that accident losses are low.

\subsection{Variable Accident Losses}

Next suppose that accident losses are variable and their magnitude is given by $l(c)=108 /(1+c)$. Under this assumption, the socially optimal level of care is $c^{*}=5$.

4.2.1. Strict Liability. Table 3 sets forth the socially optimal level of care, $c^{*}$, and the injurer's level of care, $c^{\text {sL }}$, for each possible pair $(\delta$, $\alpha)$. From Table 3 we can see the following results.

1. The injurer will take optimal care in the absence of ambiguity, 
458 / THE JOURNAL OF LEGAL STUdiES / VOLUME 36 (2) / JUNE 2007

Table 2. The Injurer's Level of Care under Negligence with Fixed Accident Losses

\begin{tabular}{lcccc}
\hline$(l, \delta, \alpha)$ & $c^{*}$ & $c^{\mathrm{SL}}$ & $F\left(c^{\mathrm{SL}}\right)$ & $c^{\mathrm{N}}$ \\
\hline$(25,0,1 / 50)$ & 4 & 4 & 9 & 4 \\
$(25,0,39 / 50)$ & 4 & 4 & 9 & 4 \\
$(25,9 / 25,1 / 50)$ & 4 & 3 & 7.18 & 4 \\
$(25,9 / 25,39 / 50)$ & 4 & 3 & 14.02 & 4 \\
$(25,21 / 25,1 / 50)$ & 4 & 1 & 3.42 & 1 \\
$(25,21 / 25,39 / 50)$ & 4 & 1 & 19.38 & 4 \\
$(36,0,1 / 50)$ & 5 & 5 & 11 & 5 \\
$(36,0,39 / 50)$ & 5 & 5 & 11 & 5 \\
$(36,9 / 25,1 / 50)$ & 5 & 3.8 & 8.86 & 5 \\
$(36,9 / 25,39 / 50)$ & 5 & 3.8 & 18.71 & 5 \\
$(36,21 / 25,1 / 50)$ & 5 & 1.4 & 4.40 & 1.4 \\
$(36,21 / 25,39 / 50)$ & 5 & 1.4 & 27.39 & 5
\end{tabular}

but in the presence of ambiguity he will exercise too little care when he is optimistic and too much care when he is pessimistic.

2. For any given degree of ambiguity, the injurer's level of care increases with his degree of pessimism.

3. The injurer's level of care decreases with ambiguity when he is optimistic and increases with ambiguity when he is pessimistic.

Figures 6 and 7 collectively illustrate all three results, each of which is consistent with proposition 4. In particular, with respect to the third result note that because $c^{\mathrm{SL}} \geq 2.44, \alpha=39 / 50>2 /\left(1+c^{\mathrm{SL}}\right)=L^{\prime}\left(c^{\mathrm{SL}}\right) /$ $l^{\prime}\left(c^{\mathrm{SL}}\right)$.

4.2.2. Negligence. Table 4 sets forth the relevant cost-benefit calculations and specifies the injurer's level of care, $c^{\mathrm{N}}$, for each possible pair $(\delta, \alpha)$. Recall that the injurer will exercise due care if $c^{*} \leq G\left(c^{\mathrm{SL}}\right) \equiv$ $c^{\mathrm{SL}}+\delta \alpha l\left(c^{\mathrm{SL}}\right)+(1-\delta) L\left(c^{\mathrm{SL}}\right)$; otherwise he will exercise $c^{\mathrm{SL}}$. From Table 4 we can see the following results.

1. The injurer will take optimal care in the absence of ambiguity if ambiguity is low or if he is pessimistic. The injurer will exercise too little care only when ambiguity is high and he is optimistic.

2. In the presence of ambiguity, the expected benefit of exercising due care increases with the injurer's degree of pessimism. Specifically, when ambiguity is low, as the injurer's degree of pessimism increases from low to high, the expected benefit of exercising due care rises from 6.91 to 11.74 . When ambiguity is high, as the injurer's degree of pessimism increases from low to high, the expected benefit of exercising due care leaps from 4.43 to 16.06 .

3. Increasing ambiguity progressively reduces the expected benefit 


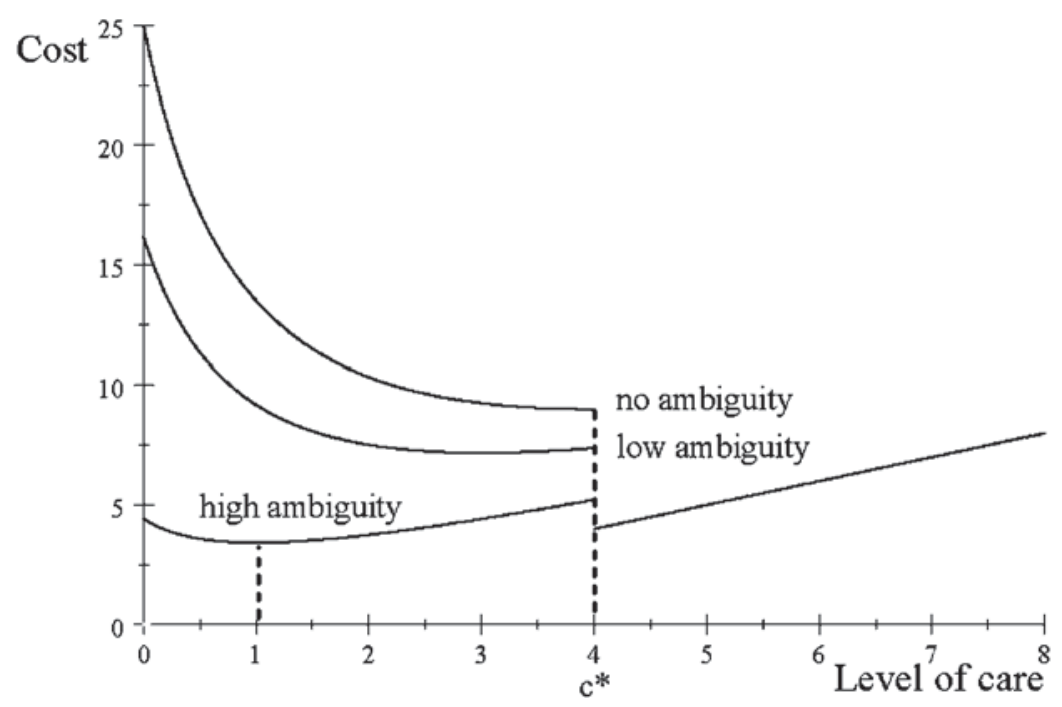

Figure 5. Effect on care of increasing ambiguity under negligence with fixed accident losses

of exercising due care if the injurer is optimistic and progressively increases it if he is pessimistic. In particular, if the injurer is optimistic, as the degree of ambiguity increases from zero to low to high, the expected benefit of exercising due care falls from 8 to 6.91 to 4.43 . If the injurer is pessimistic, however, as the degree of ambiguity increases from zero to low to high, the expected benefit of exercising due care rises from 8 to 11.74 to 16.06 .

Note that each of the results is consistent with proposition 5 .

\section{DISCUSSION}

The results of the model suggest that neither strict liability nor negligence is generally efficient in the presence of ambiguity. Under both liability rules the injurer may exercise too little care, and under strict liability he even may exercise too much care in the case of variable accident losses. In addition, the injurer's level of care generally decreases with optimism, increases with pessimism, and decreases or increases with ambiguity depending on whether he is optimistic or pessimistic, respectively.

A further implication of the results is that negligence is more robust 
460 / THE JOURNAL OF LEGAL STUdiES / VOLUME 36 (2) / JUNE 2007

Table 3. Levels of Care under Strict Liability with Variable Accident Losses

\begin{tabular}{lcl}
\hline$(\delta, \alpha)$ & $c^{*}$ & $c^{\mathrm{SL}}$ \\
\hline$(0,1 / 50)$ & 5 & 5 \\
$(0,39 / 50)$ & 5 & 5 \\
$(9 / 25,1 / 50)$ & 5 & 4.22 \\
$(9 / 25,39 / 50)$ & 5 & 6.06 \\
$(21 / 25,1 / 50)$ & 5 & 2.44 \\
$(21 / 25,39 / 50)$ & 5 & 7.65 \\
\hline
\end{tabular}

to ambiguity, which implies that negligence may be superior to strict liability in unilateral accident cases. Generally speaking, in the presence of ambiguity, strict liability is never efficient (save only a borderline case when accident losses are variable), while negligence is efficient for a range of model parameter values. More specifically, the results suggest that although we might expect the two liability rules to perform equally poorly to the extent that optimism is the prevailing attitude toward ambiguity with respect to accident risk (as the psychology literature appears to suggest), we would expect negligence to outperform strict liability in unilateral accident contexts in which people are sufficiently pessimistic (for example, where an accident is highly available in the sense used in the psychology literature). Of course, an important countervailing factor is that strict liability is less costly for a court to implement. Nevertheless, the implication that negligence is more robust to ambiguity may help explain why it is the predominant liability rule in modern tort law.

Whatever the relative merits of strict liability and negligence, the basic result remains that neither liability rule is generally efficient when the injurer faces ambiguity with respect to accident risk. The exercise then is to design a liability rule that will induce the injurer to exercise optimal care in the face of ambiguity. One approach is to modify strict liability or negligence to include an adjustment to damages, which may be positive or negative, that equates the injurer's costs with total accident costs. Let $h$ denote such adjustment. In the case of variable accident losses, ${ }^{33}$ $b$ is implicitly defined by

$$
c+\delta \alpha[l(c)+h]+(1-\delta)\{\pi(c)[l(c)+b]\}=c+\pi(c) l(c) .
$$

33. I derive $h$ for the case of variable accident losses because it is the more general case. The case of fixed accident losses is the special case in which $l(c)=l$ for some scalar $l>0$. 


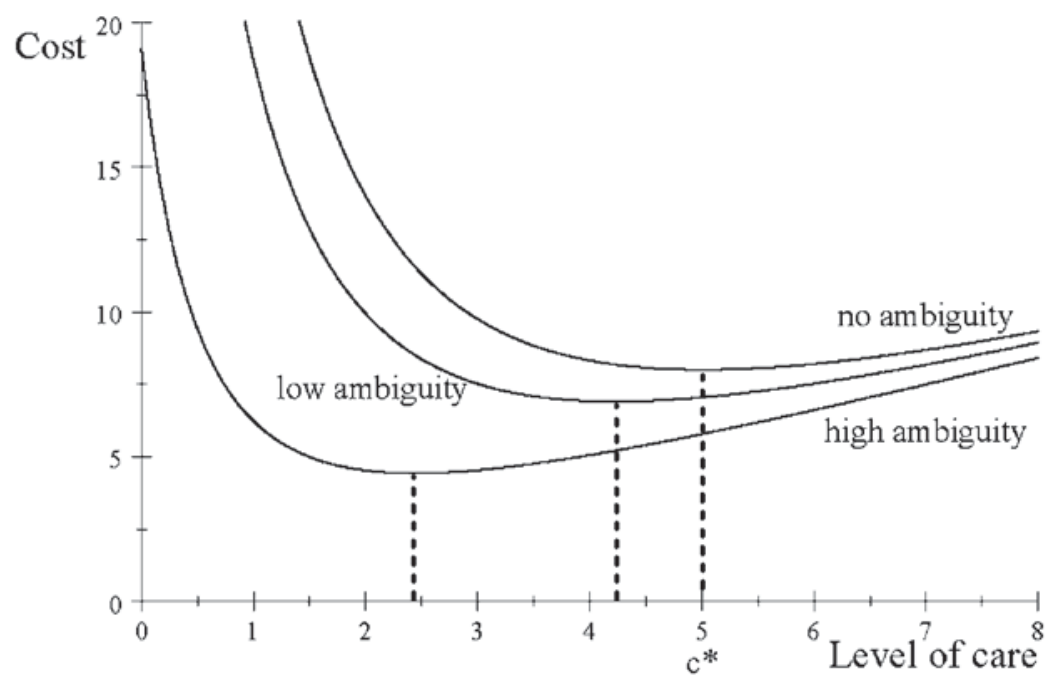

Figure 6. Effect on care of increasing ambiguity under strict liability with variable accident losses if the injurer is optimistic.

Rearranging terms gives

$$
h=\frac{\delta l(c)[\pi(c)-\alpha]}{\delta \alpha+(1-\delta) \pi(c)} .
$$

It follows immediately from equation (20) that

$$
b \gtreqless 0 \quad \text { as } \quad \pi(c) \gtreqless \alpha
$$

and that

$$
|h| \text { increases with }|\pi(c)-\alpha| \text {. }
$$

That is, (1) the adjustment will be positive when the injurer is optimistic, negative when he is pessimistic, and zero when he is neither optimistic nor pessimistic, and (2) the absolute magnitude of the adjustment increases as the injurer becomes more optimistic or pessimistic, as the case may be. Consequently, in light of the comparative statics results on optimism and pessimism, we may interpret $b$ as a scaled (by the magnitude of accident losses) ambiguity adjustment that operates to punish optimism and the resulting tendency to decrease care and to reward pessimism and the resulting tendency to increase care. It is straightforward to demonstrate the efficiency of an ambiguity-adjusted rule of strict 
462 / THE JOURNAL OF LEGAL STUdiES / VOLUME 36 (2) / JUNE 2007

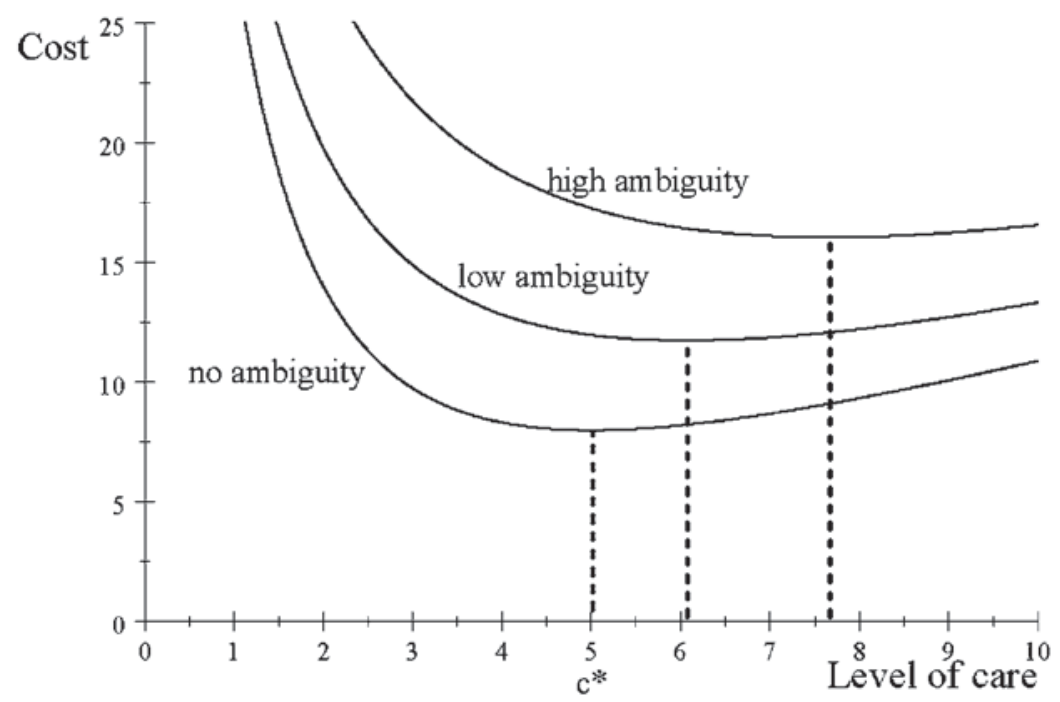

Figure 7. Effect on care of increasing ambiguity under strict liability with variable accident losses if the injurer is pessimistic.

liability or negligence. Under an ambiguity-adjusted rule of strict liability, the injurer faces equation (7) and accordingly will choose $c^{\mathrm{SL}}=c^{*}$. Under an ambiguity-adjusted negligence rule, the injurer faces equation (8) and accordingly will choose $c^{\mathrm{N}}=c^{*}$.

It is worth noting that modifying negligence to include an adjustment to the standard of due care rather than to damages is not a viable alternative approach. Suppose ambiguity would lead an injurer to exercise suboptimal care under a negligence rule with the standard of due care set equal to the socially optimal level of care. A downward adjustment of the standard of due care below the socially optimal level of care could not induce the injurer to exercise the socially optimal level of care because the injurer's level of care would never exceed the standard of due care under a rule of negligence. To see that an upward adjustment of the standard of due care above the socially optimal level of care could not induce the injurer to exercise the socially optimal level of care, consider the case of variable accident losses (which includes fixed accident losses as a special case). By assumption, the injurer would choose 
Table 4. The Injurer's Level of Care under Negligence with Variable Accident Losses

\begin{tabular}{lcccc}
\hline$(\delta, \alpha)$ & $c^{*}$ & $c^{\mathrm{SL}}$ & $G\left(c^{\mathrm{SL}}\right)$ & $c^{\mathrm{N}}$ \\
\hline$(0,1 / 50)$ & 5 & 5 & 8 & 5 \\
$(0,39 / 50)$ & 5 & 5 & 8 & 5 \\
$(9 / 25,1 / 50)$ & 5 & 4.22 & 6.91 & 5 \\
$(9 / 25,39 / 50)$ & 5 & 6.06 & 11.74 & 5 \\
$(21 / 25,1 / 50)$ & 5 & 2.44 & 4.43 & 2.44 \\
$(21 / 25,39 / 50)$ & 5 & 7.65 & 16.06 & 5 \\
\hline
\end{tabular}

$c^{\mathrm{N}}<c^{*}$ under a negligence rule with $\bar{c}=c^{*}$. This implies that $c^{\mathrm{N}}=$ $c^{\mathrm{SL}}<c^{*}$, that the injurer's decision rule is given by

$$
c^{\mathrm{N}}= \begin{cases}\bar{c} & \text { if } \bar{c} \leq G\left(c^{\mathrm{SL}}\right) \\ c^{\mathrm{SL}}<\bar{c} & \text { if } \bar{c}>G\left(c^{\mathrm{SL}}\right),\end{cases}
$$

and that $\bar{c}>G\left(c^{\mathrm{SL}}\right)$. It follows that increasing $\bar{c}$ such that $\bar{c}>c^{*}$ would not induce the injurer to choose $c^{\mathrm{N}}=c^{*}$ because it still would be the case that $\bar{c}>G\left(c^{\mathrm{SL}}\right)$ and, therefore, the injurer still would choose $c^{\mathrm{N}}=$ $c^{\mathrm{SL}}<c^{*}$.

One can imagine (at least) two objections to an ambiguity-adjusted liability rule. First, one could object that it is unworkable because the adjustment requires the court to determine the injurer's degree of and attitude toward ambiguity- $\delta$ and $\alpha$-which are unobservable. While the unobservability of $\delta$ and $\alpha$ may preclude the court from perfectly implementing the ambiguity adjustment, the court conceivably could use observable characteristics of the injurer as proxies or instruments for $\delta$ and $\alpha$ in a second-best implementation. ${ }^{34}$ Second, one could object that an ambiguity-adjusted liability rule is unfair because the adjustment to damages is based not on the injurer's acts (that is, his level of care) but rather on his beliefs (that is, his degree of and attitude toward ambiguity). Many legal determinations, however, are based on a person's state of mind. In criminal cases, for example, whether a harmful act constitutes a crime, and quite often the degree of criminal liability, depends on the defendant's state of mind, or mens rea. Perhaps more on point, courts may award exemplary or punitive damages in tort cases on the basis that the harmful act was intentional, willful, wanton, or

34. In addition, recall that, in conformity with the basic accident model, I assume the court can accurately determine all relevant facts, including the agents' preferences. Under this assumption, which is central to the basic accident model, the court would be able to determine $\delta$ and $\alpha$ and perfectly implement the ambiguity adjustment. 
malicious. In addition, the purpose of the ambiguity adjustment is not to punish or reward the injurer's beliefs but to cause the injurer to internalize the external social costs of suboptimal care. In this sense, it is analogous to a Pigouvian corrective tax and subsidy scheme and may be justified on the same grounds.

\section{CONCLUSION}

This paper generalizes the basic unilateral accident model of tort law and economics to allow for ambiguity with respect to accident risk. Standard formulations of the basic accident model are based on the expected utility framework, in which agents' beliefs about the likelihood of uncertain events are represented by probabilities. As a result, the standard models do not allow for ambiguity with respect to accident risk and cannot accommodate optimistic or pessimistic attitudes toward ambiguity. The Ellsberg paradox and related experimental evidence, however, suggest the importance of attitudes toward ambiguity for individual decision making generally. Moreover, psychology research suggests that people exhibit optimism and pessimism in the accident context.

To incorporate ambiguity into the basic unilateral accident model, I recast the model in the Choquet expected utility framework and represent the injurer's beliefs about accident risk with a neoadditive capacity. Choquet expected utility is a generalization of expected utility that allows for ambiguity. Under Choquet expected utility theory, agents' beliefs about the likelihood of uncertain events are represented by a nonadditive probability, or a capacity. The nonadditivity of the capacity allows for different attitudes toward ambiguity. A neoadditive capacity is a special type of capacity that is based on a probability distribution. That is, it is a probability weighting function. Choquet expected utility with a neoadditive capacity amounts to a weighted sum of the minimum utility, the maximum utility, and the expected utility with respect to the probability distribution on which the neoadditive capacity is based.

I represent the injurer's beliefs with a neoadditive capacity for several reasons. First, numerous empirical studies indicate that individuals weight probabilities in a manner consistent with a neoadditive capacity, and there is experimental evidence that preferences have the form suggested by Choquet expected utility with a neoadditive capacity. Second, a neoadditive capacity lends itself to concrete notions of ambiguity, optimism, and pessimism. Ambiguity corresponds to an agent's lack of 
confidence in his belief about the probability of uncertain events, while optimism and pessimism correspond to an agent overweighting the best and worst outcomes, respectively. Moreover, a neoadditive capacity parameterizes ambiguity, optimism, and pessimism, which allows me to perform comparative statics on changes in their degrees. Finally, Choquet expected utility with a neoadditive capacity is tractable and also quite general in that it includes as special cases or is mathematically equivalent to a number of alternative models of decision making under uncertainty.

The central result of the model is that, in the basic unilateral accident setting, neither strict liability nor negligence is generally efficient in the presence of ambiguity. This is in contrast to the standard results of the basic unilateral accident model, namely, that both strict liability and negligence are efficient. In particular, I show that (1) under strict liability, the injurer will exercise too little care in the case of fixed accident losses and may exercise too little or too much care in the case of variable accident losses and (2) under a negligence rule with the standard of due care set equal to the socially optimal level of care, the injurer may exercise too little care in both cases on accident losses. In addition, I find that, in general, the injurer's level of care decreases with his degree of optimism, increases with his degree of pessimism, and decreases or increases with the degree of ambiguity depending on whether the injurer is optimistic or pessimistic, respectively.

The basic intuition behind the main results may be summarized as follows. Ambiguity has two effects on the injurer's incentives to take care under strict liability. On the one hand, ambiguity leads the injurer to discount the benefit from a reduction in expected accident losses, which causes the injurer to tend to reduce his level of care. On the other hand, ambiguity leads the injurer to benefit from a reduction in the magnitude of accident losses per se, which causes the injurer to tend to increase his level of care. In the case of fixed accident losses, the injurer cannot affect the magnitude of accident losses, so only the former effect applies, and the injurer will exercise too little care. In the case of variable accident losses, whether the injurer exercises too little or too much care depends on which of the two effects dominates. The former effect will dominate and the injurer will exercise too little care if the marginal benefit from a reduction in expected accident losses exceeds the marginal benefit from a reduction in the magnitude of accident losses and the injurer is optimistic or not too pessimistic. Otherwise, the latter effect will dominate, and the injurer will exercise too much care. The injurer will take optimal care only in the borderline case in which the two effects 
466 / THE JOURNAL OF LEGAL STUdiES / VOLUME 36 (2) / JUNE 2007

perfectly offset. Under a negligence rule with the standard of due care set equal to the socially optimal level of care, the injurer faces no liability if he satisfies the standard of due care and faces strict liability otherwise. Accordingly, if per the above analysis the injurer would exercise optimal care or even too much care under strict liability, then he will take optimal care under negligence. If, however, the injurer would exercise too little care under strict liability, he may or may not exercise optimal care under negligence depending on whether the expected benefit of exercising due care, which equals his expected costs of being negligent, exceeds the cost of exercising due care, which is the price of facing no liability.

A key implication of the results of the model is that negligence is more robust to ambiguity. This suggests that negligence may be superior to strict liability in unilateral accident cases. It also may help explain why negligence is the general basis for accident liability under modern Anglo-American tort law.

The model's results and implications aside, a principal contribution of this paper is that it proposes a method to generalize the basic accident model to allow for ambiguity with respect to accident risk. The scope of the model presented is limited to the case of unilateral accidents with fixed activity levels. Natural extensions of this paper, therefore, include introducing ambiguity in the case of unilateral accidents with variable activity levels and in the more general case of bilateral accidents, including bilateral care and harm, with fixed and variable activity levels. In addition, future research could examine the implications of ambiguity for the economic analysis of other basic areas of law such as contracts, property, and criminal law, as well as other traditional law and economics topics such as litigation and settlement.

\section{APPENDIX A: CHOQUET EXPECTED UTILITY FRAMEWORK}

\section{A1. General Framework}

Let $S$ be a nonempty, finite set of states. Associated with $S$ is a set of events $\mathcal{E}$, which I take to be the power set of $S$. Let $X \subset \mathbb{R}$ be a nonempty, finite set of outcomes and let $\mathcal{F}=\{f: S \rightarrow X\}$ be a set of simple functions from states to outcomes, called simple acts. Let $u: X \rightarrow \mathbb{R}$ be a monotone increasing function from outcomes to real numbers. I interpret $u$ as a Bernoulli utility function.

I now define a capacity and the Choquet integral of a simple act with respect to a capacity.

Definition 1: Capacity. A capacity is a function $\mu: \mathcal{E} \rightarrow \mathbb{R}$ that satisfies 
monotonicity: $E, F \in \mathcal{E}$ and $E \subseteq F$ imply $\mu(E) \leq \mu(F)$; and normalization: $\mu(\varnothing)=0$ and $\mu(S)=1$.

Note that a probability distribution is a special case of a capacity that satisfies additivity: $E, F \in \mathcal{E}$, and $E \cap F=\varnothing$ imply $\mu(E)+\mu(F)=\mu(E \cup F)$.

Definition 2: Choquet Integral. Let $f: S \rightarrow X$ be a simple act that takes on the values $x_{1} \geq \cdots \geq x_{n}$. The Choquet integral of $f$ with respect to a capacity $\mu$ is defined as

$$
\int f d \mu:=\sum_{i=1}^{n} x_{i}\left[\mu\left(\left\{s \in S \mid f(s) \geq x_{i}\right\}\right)-\mu\left(\left\{s \in S \mid f(s)>x_{i}\right\}\right)\right] .
$$

I interpret the Choquet integral as the expected value of the simple act $f$ with respect to the capacity $\mu$. The Choquet integral of the composition $u(f(s))$ with respect to the capacity $\mu$ is defined as the Choquet expected utility of $f$ with respect to $\mu .^{35}$

A neoadditive capacity is a special type of capacity that is based on a probability distribution.

Definition 3: Neoadditive Capacity. Let $\delta$ and $\alpha$ be real numbers such that $0 \leq \delta, \alpha \leq 1$. A neoadditive capacity $\nu$ based on a probability distribution $p$ is defined as

$$
\nu(E):= \begin{cases}0 & \text { for } E=\varnothing \\ \delta(1-\alpha)+(1-\delta) p(E) & \text { for } \varnothing \varsubsetneqq E \varsubsetneqq S \\ 1 & \text { for } E=S .\end{cases}
$$

A neoadditive capacity is additive on nonextreme outcomes, hence the name. I interpret the additive part of a neoadditive capacity as follows: $p$ represents the agent's beliefs about the likelihood of uncertain events, and $1-\delta$ represents the agent's degree of confidence in this belief. The complement of the degree of confidence is the degree of ambiguity $\delta$.

It can be shown that the Choquet integral of a simple act $f$ with respect to a neoadditive capacity $\nu$ based on $p$ is given by

$$
\int f d \nu=\delta \alpha x_{n}+\delta(1-\alpha) x_{1}+(1-\delta) \sum_{i=1}^{n} x_{i} p\left(\left\{s \in S \mid f(s)=x_{i}\right\}\right)
$$

where $f$ takes on the values $x_{1} \geq \cdots \geq x_{n}$ (Chateauneuf, Eichberger, and Grant, forthcoming). Thus, with respect to a neoadditive capacity, the Choquet integral of a simple act $f$ is the weighted sum of the worst outcome under $f$, the best outcome under $f$, and the expected value of $f$ with respect to $p$.

35. Note that the composition $u(f(s)): S \rightarrow \mathbb{R}$ is a simple act. 
It follows that the Choquet expected utility of the simple act $f$ with respect to the neoadditive capacity $\nu$ based on $p$ is given by

$$
V_{p}(f):=\int u(f) d \nu=\delta \alpha u\left(x_{n}\right)+\delta(1-\alpha) u\left(x_{1}\right)+(1-\delta) E_{p}(f),
$$

where $E_{p}(f) \equiv \sum_{i=1}^{n} u\left(x_{i}\right) p\left(\left\{s \in S \mid u(f(s))=u\left(x_{i}\right)\right\}\right)$. That is, it is the weighted sum of the minimum utility under $f$, the maximum utility under $f$, and the expected utility of $f$ with respect to $p$. I interpret $\alpha$ as the degree of pessimism and $1-$ $\alpha$ as the degree of optimism because they determine the weights given to the minimum utility and the maximum utility. As stated above, I interpret $1-\delta$ as the degree of confidence in $p$ and $\delta$ as the degree of ambiguity. Note that in the absence of ambiguity $(\delta=0)$, Choquet expected utility reduces to expected utility.

\section{A2. The Model}

When the model is placed in this framework, the state space is $S=$ accident, no accident $\}$. The outcome space is $X=\{m(c), M(c)\}$, where $m(c)$ and $M(c)$ depend on the applicable liability rule. Because a negligence rule effectively imposes no liability if $c \leq \bar{c}$ and strict liability if $c>\bar{c}$, I need to define only $m(c)$ and $M(c)$ for the rules of no liability and strict liability. Under a rule of no liability, $m(c)=M(c)=k-c$. Under strict liability, $m(c)=k-c-l(c)$ and $M(c)=k-$ $c$. The set of acts is $\mathcal{F}=\{f(c): c \geq 0\}$, where

$$
f(c)= \begin{cases}m(c) & \text { if } s=\text { accident } \\ M(c) & \text { if } s=\text { no accident }\end{cases}
$$

The injurer's Bernoulli utility function is $u[f(c)]=f(c)$.

The injurer's beliefs about accident risk are given by a neoadditive capacity $\nu$ based on the probability distribution $p=\{\pi(c), 1-\pi(c)\}$. With a slight abuse of notation, I say that $\nu$ is based on $\pi$, and I define $\nu(\pi):=\nu$ (accident), $\nu(1-$ $\pi):=\nu$ (no accident), and $V_{\pi}(c):=V_{p}(f(c))$. In addition, I define $E_{\pi}(c):=$ $\pi(c) m(c)+[1-\pi(c)] M(c)$. It follows that the injurer's Choquet expected utility of exercising level of care $c$ under a rule of no liability or strict liability is $V_{\pi}(c)=\delta \alpha m(c)+\delta(1-\alpha) M(c)+(1-\delta) E_{\pi}(c)$ and under a negligence rule is

$$
\begin{cases}V_{\pi}(c) \text { under no liability } & \text { if } c \geq \bar{c} \\ V_{\pi}(c) \text { under strict liability } & \text { if } c<\bar{c}\end{cases}
$$

\section{A3. Relation to Other Models}

A principal advantage of Choquet expected utility with a neoadditive capacity is that it contains as special cases or is mathematically equivalent to several alternative models of decision making under uncertainty. Special cases include (see, for example, Schipper 2005) subjective expected utility, if $\delta=0$ and $\alpha \in$ 
$[0,1]$; maxmin expected utility (Wald 1950), if $\delta=1$ and $\alpha=1$; maxmax expected utility, if $\delta=1$ and $\alpha=0$; and the Hurwicz (1951) criterion, if $\delta=1$ and $\alpha \in[0,1]$. Additional special cases include maxmin expected utility with multiple priors (Gilboa and Schmeidler 1989), if $\delta \in[0,1]$ and $\alpha=1$; and maxmax expected utility with multiple priors, if $\delta \in[0,1]$ and $\alpha=0$, in each case where the set of priors is $\mathcal{D}=\{q \in \Delta: q \geq(1-\delta) p\}$ and $p$ denotes the probability distribution on which the neoadditive capacity is based (see Eichberger and Kelsey 2006).

With a neoadditive capacity $\mu$ based on $p$, Choquet expected utility is mathematically equivalent to subjective expected utility where the subjective probability of the least favorable event $W$ is $q_{W}=(1-\delta) p_{W}+\delta \alpha$, the most favorable event $B$ is $q_{B}=(1-\delta) p_{B}+\delta(1-\alpha)$, and every other event $E$ is $q_{E}=(1-\delta) p_{E}$; $\alpha$-maxmin expected utility with multiple priors (Ghirardato, Maccheroni, and Marinacci 2004) where the set of priors is $\mathcal{D}=\{q \in \Delta: q \geq(1-\delta) p\}$ (see Eichberger and Kelsey 2006; Chateauneuf, Eichberger, and Grant, forthcoming); rank-dependent expected utility with probability weighting function $\omega(p)=$ $\mu(p)$ (see Wakker 1990); and cumulative prospect theory with probability weighting function $\omega(p)=\mu(p)$ and symmetric treatment of gains and losses (see Tversky and Wakker 1995).

\section{APPENDIX B : PROOFS}

\section{B1. Social Planner's Problem}

Here I prove the assertion, made in footnote 27, that $c^{*}$ is the level of care that would be chosen by a rational social planner as part of a Pareto-optimal allocation. Let $w$ and $v$ denote the initial wealth of the injurer and the victim, respectively. Let $w_{a}$ and $v_{a}$ denote the wealth of the injurer and the victim, respectively, in the event of an accident, and let $w_{n}$ and $v_{n}$ denote the wealth of the injurer and the victim, respectively, in the event of no accident. The social planner's problem is

$$
\max _{\substack{c \geq 0 \\ w_{a}, w_{n}, v_{a}, v_{n} \geq 0}} \pi(c) v_{a}+[1-\pi(c)] v_{n}
$$

subject to

$$
\delta \alpha w_{a}+\delta(1-\alpha) w_{n}+(1-\delta)\left\{\pi(c) w_{a}+[1-\pi(c)] w_{n}\right\}=\bar{V}
$$

and

$$
\left\{\pi(c) v_{a}+[1-\pi(c)] v_{n}\right\}+\left\{\pi(c) w_{a}+[1-\pi(c)] w_{n}\right\}+c+L(c)=w+k+v .
$$

The foregoing expresses the social planner's problem as maximizing the expected utility of the victim subject to meeting a required Choquet expected utility level for the injurer $\bar{V}$ and a resource constraint in which expected resource use equals 
470 / THE JOURNAL OF LEGAL STUdiES / VOLUME 36 (2) / JUNE 2007

the available resources. Expected resource use is calculated using objective accident risk because the social planner is rational. The solution to the social planner's problem is a Pareto-optimal allocation. We may assume, without loss of generality, that $w_{a}=w_{n}$. With this assumption, the social planner's problem reduces to $\max _{c \geq 0} w+k+v-\bar{V}-c-L(c)$, which is equivalent to choosing $c \geq 0$ to minimize total accident costs $c+L(c)$. Q.E.D.

\section{B2. Proof of Proposition 2}

By assumption, $\delta \in(0,1)$. Thus, equations (5) and (11) imply $-L^{\prime}\left(c^{\mathrm{SL}}\right)=$ $1 /(1-\delta)>1=-L^{\prime}\left(c^{*}\right)$, which in turn implies $c^{\text {SL }}<c^{*}$ because $L^{\prime \prime}(c)>0$.

Implicitly differentiating equations (5) and (11) with respect to $\delta$, we have $\partial c^{\mathrm{SL}} / \partial \delta=-1 /\left[L^{\prime \prime}\left(c^{\mathrm{SL}}\right)(1-\delta)^{2}\right]<0=\partial c^{*} / \partial \delta$ because $L^{\prime \prime}(c)>0$. Hence, $c^{\mathrm{SL}}$ is decreasing in $\delta$, and the difference $c^{*}-c^{\mathrm{SL}}$ is increasing in $\delta$.

Implicitly differentiating equations (5) and (11) with respect to $l$, we have $\partial c^{*} / \partial l=-\left[\pi^{\prime}\left(c^{*}\right) / \pi^{\prime \prime}\left(c^{*}\right) l\right]>0$ and $\partial c^{\mathrm{SL}} / \partial l=-\left[\pi^{\prime}\left(c^{\mathrm{SL}}\right) / \pi^{\prime \prime}\left(c^{\mathrm{SL}}\right) l\right]>0$ because $\pi^{\prime}(c)<$ 0 and $\pi^{\prime \prime}(c)>0$. Furthermore, if $\rho_{\pi}(c)=-\left[\pi^{\prime \prime}(c) / \pi^{\prime}(c)\right]$ is a decreasing function of $c$, then $\partial c^{*} / \partial l=1 / \rho_{\pi}\left(c^{*}\right) l>1 / \rho_{\pi}\left(c^{s l}\right) l=\partial c^{\mathrm{SL}} / \partial l$ because $c^{\mathrm{SL}}<c^{*}$. Therefore, although $c^{\mathrm{sL}}$ is increasing in $l$, the difference $c^{*}-c^{\mathrm{sL}}$ is increasing in $l$ if $\pi(c)$ exhibits decreasing local convexity. Q.E.D.

\section{B3. Proof of Proposition 3}

Recall that $F\left(c^{\mathrm{SL}}\right) \equiv c^{\mathrm{SL}}+\delta \alpha l+(1-\delta) L\left(c^{\mathrm{SL}}\right)$. Equation (13) immediately implies $c^{\mathrm{N}} \leq c^{*}$ because model parameters exist such that $c^{*} \leq F\left(c^{\mathrm{SL}}\right)$ and $c^{*}>F\left(c^{\mathrm{SL}}\right)$. For example, suppose $\pi(c)=1 /(1+c), l=49, \delta=24 / 49$, and $\alpha=1 / 5$. It follows that $c^{*}=6.0 \leq 13.8=F\left(c^{\mathrm{SL}}\right)$. Now suppose $\pi(c)=1 /(1+c), l=49, \delta=$ $45 / 49$, and $\alpha=1 / 100$. Then we have $c^{*}=6.0>3.45=F\left(c^{\mathrm{SL}}\right)$.

Now, by the envelope theorem, $\partial F\left(c^{\mathrm{SL}}\right) / \partial \delta=\alpha l-L\left(c^{\mathrm{SL}}\right)=\left[\alpha-\pi\left(c^{\mathrm{SL}}\right)\right] l$. It follows that $\partial F\left(c^{\mathrm{SL}}\right) / \partial \delta<0=\partial c^{*} / \partial \delta$ if $\alpha<\pi\left(c^{\mathrm{SL}}\right)$ and that $\partial F\left(c^{\mathrm{SL}}\right) / \partial \delta>0=\partial c^{*} / \partial \delta$ if $\alpha>\pi\left(c^{\mathrm{SL}}\right)$. Thus, the likelihood that $F\left(c^{\mathrm{SL}}\right)<c^{*}$, and therefore that $c^{\mathrm{SL}}<c^{*}$, increases with $\delta$ if the injurer is optimistic and decreases with $\delta$ if the injurer is pessimistic.

In addition, by the envelope theorem, $\partial F\left(c^{\mathrm{SL}}\right) / \partial \alpha=\delta l>0=\partial c^{*} / \partial \alpha$. Hence, the likelihood that $F\left(c^{\mathrm{SL}}\right)<c^{*}$, and therefore that $c^{\mathrm{SL}}<c^{*}$, increases with $1-\alpha$ and decreases with $\alpha$.

Finally, by the envelope theorem, $\partial F\left(c^{\mathrm{SL}}\right) / \partial l=\delta \alpha+(1-\delta) \pi\left(c^{\mathrm{SL}}\right)$, which implies that $\partial F\left(c^{\mathrm{SL}}\right) / \partial l \gtreqless \partial c^{*} / \partial l$ as $\delta \alpha+(1-\delta) \pi\left(c^{\mathrm{SL}}\right) \gtreqless 1 / \rho_{\pi}\left(c^{*}\right) l$, or as $F\left(c^{\mathrm{SL}}\right)-$ $c^{\mathrm{SL}} \gtreqless 1 / \rho_{\pi}\left(c^{*}\right)$. Thus, the likelihood that $F\left(c^{\mathrm{SL}}\right)<c^{*}$, and therefore that $c^{\mathrm{SL}}<c^{*}$, increases with $l$ if $F\left(c^{\mathrm{SL}}\right)-c^{\mathrm{SL}}<1 / \rho_{\pi}\left(c^{*}\right)$ and decreases with $l$ if $F\left(c^{\mathrm{SL}}\right)-c^{\mathrm{SL}}>$ $1 / \rho_{\pi}\left(c^{*}\right)$. Q.E.D. 


\section{B4. Proof of Proposition 4}

Equation (16) immediately implies $c^{\mathrm{SL}} \lesseqgtr c^{*}$ because model parameters exist such that $-l^{\prime}\left(c^{\mathrm{SL}}\right) \lesseqgtr \frac{1}{\alpha}$. For example, suppose $\pi(c)=1 /(1+c), l(c)=1,000 e^{-c}, \delta=$ $9 / 10$, and $\alpha=1 / 9$. It follows that $c^{\mathrm{SL}}=4.7896$ and $-l^{\prime}\left(c^{\mathrm{SL}}\right)=1,000 e^{-4.7896}=$ $8.3<9=\frac{1}{\alpha}$. Now suppose $\pi(c)=1 /(1+c), l(c)=1,000 e^{-c}, \delta=9 / 10$, and $\alpha=$ 2/9. It follows that $c^{\mathrm{SL}}=5.385$ and $-l^{\prime}\left(c^{\mathrm{SL}}\right)=1,000 e^{-5.385}=4.6>4.5=\frac{1}{\alpha}$. Finally, suppose $\pi(c)=1 /(1+c), l(c)=1,000 e^{-c}, \delta=9 / 10$, and $\alpha=.18636$. It follows that $c^{\mathrm{SL}}=c^{*}=5.2277$ and $-l^{\prime}\left(c^{\mathrm{SL}}\right)=1,000 e^{-5.2277}=5.366=\frac{1}{\alpha}$. Note that this is a borderline case because $(c, \alpha)=(5.2277, .18636)$ is the unique pair that simultaneously satisfies equations (5) and (15).

Implicitly differentiating equation (15) with respect to $\alpha$, we have $\partial c^{\mathrm{SL}} / \partial \alpha=-\delta l^{\prime}\left(c^{\mathrm{SL}}\right) /\left[(1-\delta) L^{\prime \prime}\left(c^{\mathrm{SL}}\right)+\delta \alpha l^{\prime \prime}\left(c^{S L}\right)\right]>0$ because $l^{\prime}(c)<0, l^{\prime \prime}(c)>0$, and $L^{\prime \prime}(c)>0$. Thus, $c^{\mathrm{SL}}$ is increasing in $\alpha$ and decreasing in $1-\alpha$. Furthermore, $\partial c^{\mathrm{SL} / \partial \alpha}>0$ and $l^{\prime}(c)<0$ imply that $-l^{\prime}\left(c^{\mathrm{SL}}\right)$ is increasing in $\alpha$. Hence, since $\frac{1}{\alpha}$ is decreasing in $\alpha$, the likelihood that $-l^{\prime}\left(c^{\mathrm{SL}}\right)<\frac{1}{\alpha}$, and therefore that $c^{\mathrm{SL}}<c^{*}$, is increasing in $1-\alpha$ and decreasing in $\alpha$. Conversely, the likelihood that $-l^{\prime}\left(c^{\mathrm{SL}}\right)>\frac{1}{\alpha}$, and therefore that $c^{\mathrm{SL}}>c^{*}$, is decreasing in $1-\alpha$ and increasing in $\alpha$.

Implicitly differentiating equation (15) with respect to $\delta$, we have $\partial c^{\mathrm{SL}} / \partial \delta=\left[L^{\prime}\left(c^{\mathrm{SL}}\right)-\alpha l^{\prime}\left(c^{\mathrm{SL}}\right)\right] /\left[(1-\delta) L^{\prime \prime}\left(c^{\mathrm{SL}}\right)+\delta \alpha l^{\prime \prime}\left(c^{\mathrm{SL}}\right)\right]$. Note that $(1-\delta) L^{\prime \prime}\left(c^{\mathrm{SL}}\right)+$ $\delta \alpha l^{\prime \prime}\left(c^{\mathrm{SL}}\right)>0$ because $L^{\prime \prime}(c)>0$ and $l^{\prime \prime}(c)>0$. So $\partial c^{\mathrm{SL}} / \partial \delta \gtreqless 0$ as $L^{\prime}\left(c^{\mathrm{SL}}\right)-\alpha l^{\prime}\left(c^{\mathrm{SL}}\right) \gtreqless 0$, or as $\alpha \gtreqless L^{\prime}\left(c^{\mathrm{SL}}\right) / l^{\prime}\left(c^{\mathrm{SL}}\right)$. Now $L^{\prime}\left(c^{\mathrm{SL}}\right) / l^{\prime}\left(c^{\mathrm{SL}}\right)=\left[\pi^{\prime}\left(c^{\mathrm{SL}}\right) l\left(c^{\mathrm{SL}}\right)+\pi\left(c^{\mathrm{SL}}\right) l^{\prime}\left(c^{\mathrm{SL}}\right)\right] / l^{\prime}\left(c^{\mathrm{SL}}\right)=$ $\pi^{\prime}\left(c^{\mathrm{SL}}\right) l\left(c^{\mathrm{SL}}\right) / l^{\prime}\left(c^{\mathrm{SL}}\right)+\pi\left(c^{\mathrm{SL}}\right)>\pi\left(c^{\mathrm{SL}}\right)$ because $\pi^{\prime}(c)>0$ and $l^{\prime}(c)>0$. It follows that $\partial c^{\mathrm{SL} / \partial \delta<0}$ if $\alpha<\pi\left(c^{\mathrm{SL}}\right)<L^{\prime}\left(c^{\mathrm{SL}}\right) / l^{\prime}\left(c^{\mathrm{SL}}\right)$ or if $\pi\left(c^{\mathrm{SL}}\right)<\alpha<L^{\prime}\left(c^{\mathrm{SL}}\right) / l^{\prime}\left(c^{\mathrm{SL}}\right)$ and that $\partial c^{\mathrm{SL}} / \partial \delta>0$ if $\alpha>L^{\prime}\left(c^{\mathrm{SL}}\right) / l^{\prime}\left(c^{\mathrm{SL}}\right)>\pi\left(c^{\mathrm{SL}}\right)$. Thus, $c^{\mathrm{SL}}$ is decreasing in $\delta$ if the injurer is optimistic or if he is pessimistic and $\alpha<L^{\prime}\left(c^{\mathrm{SL}}\right) / l^{\prime}\left(c^{\mathrm{SL}}\right)$ and $c^{\mathrm{SL}}$ is increasing in $\delta$ if the injurer is pessimistic and $\alpha>L^{\prime}\left(c^{\mathrm{SL}}\right) / l^{\prime}\left(c^{\mathrm{SL}}\right)$.

Now $l^{\prime}(c)<0$ implies that $-l^{\prime}\left(c^{\mathrm{SL}}\right)$ is decreasing in $\delta$ if $\partial c^{\mathrm{SL}} / \partial \delta<0$ and increasing in $\delta$ if $\partial c^{\mathrm{SL}} / \partial \delta>0$. Thus, since $\frac{1}{\alpha}$ is independent of $\delta$, it follows that the likelihood that $-l^{\prime}\left(c^{\mathrm{SL}}\right)<\frac{1}{\alpha}$, and therefore that $c^{\mathrm{SL}}<c^{*}$, is increasing in $\delta$ if the injurer is optimistic or if he is pessimistic and $\alpha<L^{\prime}\left(c^{\mathrm{SL}}\right) / l^{\prime}\left(c^{\mathrm{SL}}\right)$ and decreasing in $\delta$ if the injurer is pessimistic and $\alpha<L^{\prime}\left(c^{\mathrm{SL}}\right) / l^{\prime}\left(c^{\mathrm{SL}}\right)$. Conversely, the likelihood that $-l^{\prime}\left(c^{\mathrm{SL}}\right)>\frac{1}{\alpha}$, and therefore that $c^{\mathrm{SL}}>c^{*}$, is decreasing in $\delta$ if the injurer is optimistic or if he is pessimistic and $\alpha<L^{\prime}\left(c^{\mathrm{SL}}\right) / l^{\prime}\left(c^{\mathrm{SL}}\right)$ and increasing in $\delta$ if the injurer is pessimistic and $\alpha<L^{\prime}\left(c^{\mathrm{SL}}\right) / l^{\prime}\left(c^{\mathrm{SL}}\right)$. Q.E.D.

\section{B5. Proof of Proposition 5}

Recall that $G\left(c^{\mathrm{SL}}\right) \equiv c^{\mathrm{SL}}+\delta \alpha l\left(c^{\mathrm{SL}}\right)+(1-\delta) L\left(c^{\mathrm{SL}}\right)$. In the proof of proposition 4, I show that model parameters exist such that $-l^{\prime}\left(c^{\mathrm{SL}}\right) \lesseqgtr \frac{1}{\alpha}$. Thus, to establish that $c^{\mathrm{N}} \leq c^{*}$, it is sufficient to show that model parameters exist such that $c^{*}>$ $G\left(c^{\mathrm{SL}}\right)$. Suppose $\pi(c)=1 /(1+c), l(c)=1,000 e^{-c}, \delta=99 / 100$, and $\alpha=1 / 99$. It 
follows that $c^{*}=5.2277$ and $c^{\mathrm{SL}}=2.6058^{36}$ and that $G\left(c^{\mathrm{SL}}\right)=2.6058+$ $(99 / 100)(1 / 99)\left(1,000 e^{-2.6058}\right)+[1-(99 / 100)][1 /(1+2.6058)]\left(1,000 e^{-2.6058}\right)=$ $3.549<5.2277=c^{*}$.

Now, by the envelope theorem, $\partial G\left(c^{\mathrm{SL}}\right) / \partial \delta=\alpha l\left(c^{\mathrm{SL}}\right)-L\left(c^{\mathrm{SL}}\right)=[\alpha-$ $\left.\pi\left(c^{\mathrm{SL}}\right)\right] l\left(c^{\mathrm{SL}}\right)$. It follows that $\partial G\left(c^{\mathrm{SL}}\right) / \partial \delta<0=\partial c^{*} / \partial \delta$ if $\alpha<\pi\left(c^{\mathrm{SL}}\right)$ and that $\partial G\left(c^{\mathrm{SL}}\right) / \partial \delta>0=\partial c^{*} / \partial \delta$ if $\alpha>\pi\left(c^{\mathrm{SL}}\right)$. Thus, the likelihood that $G\left(c^{\mathrm{SL}}\right)<c^{*}$, and therefore that $c^{\mathrm{SL}}<c^{*}$, increases with $\delta$ if the injurer is optimistic and decreases with $\delta$ if the injurer is pessimistic.

Finally, by proposition 4 , the likelihood that $-l^{\prime}\left(c^{\mathrm{SL}}\right) \geq \frac{1}{\alpha}$, and therefore that $c^{\mathrm{N}}=c^{*}$, increases with $\alpha$ and decreases with $1-\alpha$. If $-l^{\prime}\left(c^{\mathrm{SL}}\right)<\frac{1}{\alpha}$, the likelihood that $c^{*} \leq G\left(c^{\mathrm{SL}}\right)$, and therefore that $c^{\mathrm{N}}=c^{*}$, increases with $\alpha$ and decreases with $1-\alpha$ because, by the envelope theorem, $\partial G / \partial \alpha=\delta l\left(c^{\mathrm{SL}}\right)>0$. It follows that the likelihood that the injurer will choose $c^{\mathrm{N}}=c^{*}$ increases with $\alpha$ and decreases with $1-\alpha$, which implies the likelihood that the injurer will choose $c^{\mathrm{N}}<c^{*}$ increases with $1-\alpha$ and decreases with $\alpha$. Q.E.D.

\section{REFERENCES}

Anscombe, Francis J., and Robert J. Aumann. 1963. A Definition of Subjective Probability. Annals of Mathematical Statistics 34:199-205.

Arlen, Jennifer H. 1990. Re-examining Liability Rules When Injurers as Well as Victims Suffer Losses. International Review of Law and Economics 10: 233-39.

- 1992. Liability for Physical Injury When Injurers as Well as Victims Suffer Losses. Journal of Law, Economics, and Organization 8:411-26.

Bar-Gill, Oren. 2006. The Evolution and Persistence of Optimism in Litigation. Journal of Law, Economics, and Organization 22:490-507.

Basili, Marcello, and Carlo Zappia. 2000. Radical Ignorance in Individual Decision Making: Assessing Austrian Subjectivism. Working Paper No. 289. University of Siena, Department of Economics.

- 2003a. Probabilistic versus Non-probabilistic Decision Making: Savage, Shackle and Beyond. Working Paper No. 403. University of Siena, Department of Economics.

. 2003b. Shackle's Economic Agent and Modern Decision Theory. Working Paper No. 394. University of Siena, Department of Economics.

- 2006. Ambiguity and Uncertainty in Ellsberg and Shackle. Paper presented at the twelfth international conference on the Foundations and Applications of Utility, Risk and Decision Theory, Rome.

Becker, Selwyn W., and Fred O. Brownson. 1964. What Price Ambiguity? Or 36. Note that $-l^{\prime}\left(c^{\mathrm{SL}}\right)=1,000 e^{-2.6058}=73.844<99=1 / \alpha$. 
the Role of Ambiguity in Decision-Making. Journal of Political Economy 72: 62-73.

Bigus, Jochen. 2006. Tort Liability and Probability Weighting Function According to Prospect Theory. Paper presented at the sixteenth annual meeting of the American Law and Economics Association, Berkeley, Calif.

Brown, John P. 1973. Toward an Economic Theory of Liability. Journal of Legal Studies 2:323-49.

Bouckaert, Boudewijn, and Gerrit De Geest, eds. 2000. Civil Law and Economics. Vol. 2 of Encyclopedia of Law and Economics. Cheltenham: Edward Elgar.

Camerer, Colin. 1995. Individual Decision Making. Pp. 587-703 in The Handbook of Experimental Economics, edited by John. H. Hagel and Alvin. E. Roth. Princeton, N.J.: Princeton University Press.

Camerer, Colin, and Martin Weber. 1992. Recent Developments in Modeling Preferences: Uncertainty and Ambiguity. Journal of Risk and Uncertainty 5: 325-70.

Chateauneuf, Alain, Jürgen Eichberger, and Simon Grant. Forthcoming. Choice under Uncertainty with the Best and Worst in Mind: Neo-additive Capacities. Journal of Economic Theory.

Choquet, Gustave. 1954. Theory of Capacities. Annales de l'institute Fourier 5: 131-295.

Chorvat, Terrence. R. 2002. Ambiguity and Income Taxation. Cardozo Law Review 23:617-51.

Coase, R. H. 1960. The Problem of Social Cost. Journal of Law and Economics $3: 1-44$.

Covello, Vincent T., and Branden B. Johnson. 1987. The Social and Cultural Construction of Risk: Issues, Methods, and Case Studies. Pp. vii-xiii in The Social and Cultural Construction of Risk: Essays on Risk Selection and Perception, edited by Branden B. Johnson and Vincent T. Covello. Dordrecht: D. Reidel Publishing Company.

Craswell, Richard, and John E. Calfee. 1986. Deterrence and Uncertain Legal Standards. Journal of Law, Economics, and Organization 2:279-303.

DeJoy, David M. 1989. The Optimism Bias and Traffic Accident Risk Perception. Accident Analysis and Prevention 21:333-40.

Dobbs, Dan B. 2001. The Law of Torts. St. Paul, Minn.: West Group.

Eichberger, Jürgen, and David Kelsey. 2006. Optimism and Pessimism in Games. Working paper. University of Exeter, Department of Economics.

Eichberger, Jürgen, David Kelsey, and Burkhard C. Schipper. 2007. Ambiguity and Social Interaction. Working paper. http://ssrn.com/abstract $=464242$.

Eide, Erling. 2005. Accident Liability with Rank Dependent Expected Utility. Paper presented at the twenty-second annual meeting of the European Association for Law and Economics, Ljubljana. 
474 / THE JOURNAL OF LEGAL STUdiES / VOLUME 36 (2) / JUNE 2007

2007. Accident Liability with Rank Dependence. Kritische Vierteljahresschrift für Gesetzgebung und Rechtswissenschaft 1/2:160-71.

Ellsberg, Daniel. 1961. Risk, Ambiguity, and the Savage Axioms. Quarterly Journal of Economics 75:643-69.

Finn, Peter, and Barry W. E. Bragg. 1986. Perception of the Risk of an Accident by Younger and Older Drivers. Accident Analysis and Prevention 18:289-98.

Ford, James L., David Kelsey, and Wei Pang. 2006. Information and Ambiguity: Contrarian and Herd Behaviour in Financial Markets. Working paper. University of Birmingham, Department of Economics.

Ghirardato, Paolo, Fabio Maccheroni, and Massimo Marinacci. 2004. Differentiating Ambiguity and Ambiguity Attitude. Journal of Economic Theory 118:133-73.

Gigerenzer, Gerd. 2005. Is the Mind Irrational or Ecologically Rational? Pp. 37-67 in The Law and Economics of Irrational Behavior, edited by Francesco Parisi and Vernon L. Smith. Stanford, Calif.: Stanford University Press.

Gilboa, Itzhak. 1987. Expected Utility with Purely Subjective Non-additive Probabilities. Journal of Mathematical Economics 16:65-88.

Gilboa, Itzhak, and David Schmeidler. 1989. Maxmin Expected Utility with a Non-unique Prior. Journal of Mathematical Economics 18:141-53.

Gonzalez, Richard, and George Wu. 1999. On the Shape of the Probability Weighting Function. Cognitive Psychology 38:129-66.

Guppy, Andrew. 1992. Subjective Probability of Accident and Apprehension in Relation to Self-Other Bias, Age, and Reported Behavior. Accident Analysis and Prevention 25:375-82.

Hong, Chew Soo, and Peter Wakker. 1996. The Comonotonic Sure-Thing Principle. Journal of Risk and Uncertainty 12:5-27.

Hurwicz, Leonid. 1951. Optimality Criteria for Decision-Making under Ignorance. Discussion Paper No. 370. Cowles Commission for Research in Economics, New Haven, Conn.

Hylton, Keith N. 1990. Costly Litigation and Legal Error under Negligence. Journal of Law and Economics 6:433-52.

Jolls, Christine. 1998. Behavioral Economic Analysis of Redistributive Legal Rules. Vanderbilt Law Review 51:1653-77.

Jolls, Christine, Cass R. Sunstein, and Richard Thaler. 1998. A Behavioral Approach to Law and Economics. Stanford Law Review 50:1471-1550.

Kahneman, Daniel, and Amos Tversky. 1979. Prospect Theory: An Analysis of Decision under Risk. Econometrica 47:263-91.

Kaplow, Louis, and Steven Shavell. 2001. Any Non-welfarist Method of Policy Assessment Violates the Pareto Principle. Journal of Political Economy 109: 281-86.

- 2002a. Economic Analysis of Law. In Handbook of Public Economics, vol. 3, pp. 1661-1784, edited by Alan J. Auerbach and Martin Feldstein. Amsterdam: Elsevier. 
_. 2002b. Fairness versus Welfare. Cambridge, Mass.: Harvard University Press.

Knight, Frank H. 1921. Risk, Uncertainty and Profit. Boston: Hougthon Mifflin. Landes, William M., and Richard A. Posner. 1987. The Economic Structure of Tort Law. Cambridge, Mass.: Harvard University Press.

Leong, Avon K. 1989. Liability Rules When Injurers as Well as Victims Suffer Losses. International Review of Law and Economics 9:105-11.

Lichtenstein, Sarah, Paul Slovic, Baruch Frischhoff, Mark Layman, and Barbara Combs. 1978. Judged Frequency of Lethal Events. Journal of Experimental Psychology: Human Learning and Memory 4:551-78.

Lopes, Lola L. 1987. Between Hope and Fear: The Psychology of Risk. In Advances in Experimental Social Psychology, vol. 20, pp. 255-95, edited by Leonard Berkowitz. New York: Academic Press.

Mas-Collel, Andreu, Michael D. Whinston, and Jerry R. Green. 1995. Microeconomic Theory. New York: Oxford University Press.

Matthews, Michael L., and Andrew R. Moran. 1986. Age Differences in Male Drivers' Perception of Accident Risk: The Role of Perceived Driving Ability. Accident Analysis and Prevention 18:299-313.

Mattiacci, Giuseppe Dari, and Francesco Parisi. 2005. The Economics of Tort Law. Pp. 87-102 in The Elgar Companion to Law and Economics, edited by Jürgen G. Backaus. 2d ed. Cheltenham: Edward Elgar.

McKenna, Frank P., Robert A. Stainer, and Clive Lewis. 1991. Factors Underlying Illusory Self-Assessment of Driving Skill in Males and Females. Accident Analysis and Prevention 23:45-52.

Miceli, Thomas J. 1997. Economics of the Law: Torts, Contracts, Property, Litigation. New York: Oxford University Press.

Mukerji, Sujor, and Jean-Marc Tallon. 2004. An Overview of Economic Applications of David Schmeidler's Models of Decision Making under Uncertainty. Pp. 283-302 in Uncertainty in Economic Theory: Essays in Honor of David Schmeidler's 65th Birthday, edited by Itzhak Gilboa. London: Routledge.

Parisi, Francesco, and Vernon L. Smith, eds. 2005. The Law and Economics of Irrational Behavior. Stanford, Calif.: Stanford University Press.

Posner, Eric A. 2003. Probability Errors: Some Positive and Normative Implications for Tort and Contract Law. Supreme Court Economic Review 11: $125-41$.

Quiggin, John. 1982. A Theory of Anticipated Utility. Journal of Economic Behavior and Organization 3:323-43.

- 1 1993. Generalized Expected Utility Theory: The Rank Dependent Model. Boston: Kluwer Academic Publishers.

Sarin, Rakesh, and Peter Wakker. 1992. A Simple Axiomatization of Nonadditive Expected Utility. Econometrica 60:1255-72.

- 1998. Revealed Likelihood and Knightian Uncertainty. Journal of Risk and Uncertainty 16:223-50. 
476 / THE JOURNAL OF LEGAL STUdiES / VOLUME 36 (2) / JUNE 2007

Savage, Leonard J. 1954. The Foundations of Statistics. New York: John Wiley. Schipper, Burkhard C. 2005. The Evolutionary Stability of Optimism, Pessimism and Complete Ignorance. Discussion Paper No. 35/2005. University of Bonn, Department of Economics.

Schmeidler, David. 1989. Subjective Probability and Expected Utility without Additivity. Econometrica 57:571-87.

Segal, Uzi, and Alex Stein. 2006. Ambiguity Aversion and the Criminal Process. Notre Dame Law Review 81:1495-1551.

Shackle, G. L. S. 1949. Expectations in Economics. Cambridge: Cambridge University Press.

-1955. Uncertainty in Economics and Other Reflections. Cambridge: Cambridge University Press.

- 1961. Decision, Order and Time in Human Affairs. Cambridge: Cambridge University Press.

Shavell, Steven. 1980. Strict Liability versus Negligence. Journal of Legal Studies 9:1-25.

- 1982. On Liability and Insurance. Bell Journal of Economics 13:120-32.

- 1985. Uncertainty over Causation and the Determination of Civil Liability. Journal of Law and Economics 28:587-609.

- 1986. The Judgment Proof Problem. International Review of Law and Economics 6:45-58.

- 1987. Economic Analysis of Accident Law. Cambridge, Mass.: Harvard University Press.

- 1992. Liability and the Incentive to Obtain Information about Risk. Journal of Legal Studies 21:259-70.

Slovic, Paul, Baruch Frischhoff, and Sarah Lichtenstein. 1982. Facts versus Fears: Understanding Perceived Risk. Pp. 462-92 in Judgement under Uncertainty: Heuristics and Biases, edited by Daniel Kahnemann, Paul Slovic, and Amos Tversky. Cambridge: Cambridge University Press.

Sunstein, Cass R. 1997. Behavioral Analysis of Law. University of Chicago Law Review 64:1175-95.

—_ ed. 2000. Behavioral Law and Economics. Cambridge: Cambridge University Press.

Svenson, Ola. 1981. Are We All Less Risky and More Skillful Than Our Fellow Drivers? Acta Psychologica 47:143-48.

Svenson, Ola, Baruch Frischhoff, and Donald MacGregor. 1985. Perceived Driving Safety and Seatbelt Usage. Accident Analysis and Prevention 17:119-33.

Tversky, Amos, and Daniel Kahneman. 1992. Advances in Prospect Theory: Cumulative Representation of Uncertainty. Journal of Risk and Uncertainty 5:297-323.

Tversky, Amos, and Peter Wakker. 1995. Risk Attitudes and Decision Weights. Econometrica 63:1255-80. 
Viscusi, W. Kip. 1992. Fatal Tradeoffs: Public and Private Responsibilities for Risk. New York: Oxford University Press.

Viscusi, W. Kip, and Wesley A. Magat. 1987. Learning about Risk: Consumer and Worker Responses to Hazard Warnings. Cambridge, Mass.: Harvard University Press.

von Neumann, John, and Oskar Morgenstern. 1944. Theory of Games and Economic Behavior. Princeton, N.J.: Princeton University Press.

Wakker, Peter. 1990. Under Stochastic Dominance Choquet-Expected Utility and Anticipated Utility Are Identical. Theory and Decision 29:119-32.

- 2001. Testing and Characterizing Properties of Nonadditive Measures through Violations of the Sure-Thing Principle. Econometrica 69:1039-59. Wald, Abraham. 1950. Statistical Decision Functions. New York: John Wiley.

Weinstein, Neil D. 1980. Unrealistic Optimism about Future Life Events. Journal of Personality and Social Psychology 39:806-20.

1989. Optimistic Biases about Personal Risks. Science 246:1232-33.

1999. What Does It Mean to Understand a Risk? Evaluating Risk Comprehension. Journal of the National Cancer Institute Monographs 25:15-20.

Zappia, Carlo, and Marcello Basili. 2005. Shackle versus Savage: Non-probabilistic Alternatives to Subjective Probability Theory in the 1950s. Working Paper No. 452. University of Siena, Department of Economics. 